\title{
TITLE: LRRC15 suppresses SARS-CoV-2 infection and controls collagen production
}

Authors

Lipin Loo ${ }^{1,5}$, Matthew A. Waller ${ }^{1,5}$, Alexander J. Cole ${ }^{2}$, Alberto Ospina Stella ${ }^{3}$, Cesar L. Moreno $^{1}$, Christopher E. Denes ${ }^{1}$, Zina Hamoudi ${ }^{1}$, Felicity Chung ${ }^{1}$, Anupriya Aggarwal ${ }^{3}$, Jason

K. K. Low ${ }^{4}$, Karishma Patel ${ }^{4}$, Rezwan Siddique ${ }^{4}$, Joel Mackay, Stuart Turville ${ }^{3}$, Daniel Hesselson $^{2}$, G. Gregory Neely ${ }^{1,6}$

Affiliations

${ }^{1}$ Charles Perkins Centre, Dr. John and Anne Chong Lab for Functional Genomics, Centenary Institute, and School of Life and Environmental Sciences, University of Sydney, Camperdown, NSW, Australia.

${ }^{2}$ Centenary Institute and Faculty of Medicine and Health, The University of Sydney, Sydney,

NSW, 2006, Australia

${ }^{3}$ The

${ }^{4}$ School of Life and Environmental Sciences, The University of Sydney, Sydney, New South Wales 2006, Australia.

${ }^{5}$ These authors contributed equally

$24{ }^{6}$ Lead contact

*Correspondence: greg.neely@ sydney.edu.au (G.G.N.)

\section{In Brief}

Using pooled whole genome CRISPR activation screening, we identify the TLR relative LRRC15 as a novel SARS-CoV-2 Spike interacting protein. LRRC15 is not a SARS-CoV-2 entry receptor, but instead can suppress SARS-CoV-2 infection. LRRC15 is expressed by lung fibroblasts and regulates both collagen production and infection of ACE2-expressing target cells. This may provide a direct link between SARS-CoV-2 particles and lung fibrosis seen in "longhaul" COVID-19 patients.

\section{Highlights}

- Whole genome CRISPR activation screening implicates the TLR relative LRRC15 in SARS-CoV-2 Spike binding

- LRRC15 suppresses live SARS-CoV-2 virus infection 
- LRRC15 is expressed in lung fibroblasts and sequesters virus while controlling collagen production

- LRRC15 can act as a master regulator of infection and fibrosis, potentially controlling SARS-CoV-2 infection outcomes and "long-haul" COVID-19

\section{Summary}

Although ACE2 is the primary receptor for SARS-CoV-2 infection, a systematic assessment of factors controlling SARS-CoV-2 host interactions has not been described. Here we used whole genome CRISPR activation to identify host factors controlling SARS-CoV-2 Spike binding. The top hit was a Toll-like receptor-related cell surface receptor called leucine-rich repeat-containing protein 15 (LRRC15). LRRC15 expression was sufficient to promote SARS-CoV-2 Spike binding where it forms a cell surface complex with LRRC15 but does not support infection. Instead, LRRC15 functioned as a negative receptor suppressing both pseudotyped and live SARS-CoV-2 infection. LRRC15 is expressed in collagen-producing lung myofibroblasts where it can sequester virus and reduce infection in trans. Mechanistically LRRC15 is regulated by TGF- $\beta$, where moderate LRRC15 expression drives collagen production but high levels suppress it, revealing a novel lung fibrosis feedback circuit. Overall, LRRC15 is a master regulator of SARS-CoV-2, suppressing infection and controlling collagen production associated with "longhaul" COVID-19.

\section{Keywords}

LRRC15, SARS-CoV-2, COVID-19, Spike, CRISPR activation screen, gain of function, longhaul COVID-19

\section{Introduction}

The Coronavirus 2019 (COVID-19) pandemic, caused by SARS-CoV-2, represents the greatest public health challenge of our time. As of November 2021, there have been over 250,000,000 reported cases of COVID-19 globally and in excess of 5,000,000 subsequent deaths (WHO). SARS-CoV-2 shows high sequence similarity (79.6\%) with severe acute respiratory syndrome coronavirus (SARS-CoV-1), and because of this similarity, angiotensin-converting enzyme 2 (ACE2), the primary entry receptor for SARS-CoV-1, was quickly identified as the SARS-CoV2 Spike receptor (Kuba et al., 2005; Li et al., 2003; Lu et al., 2020; Zhou et al., 2020). However, a comprehensive search for other host factors that promote SARS-CoV-2 Spike binding has not yet been reported.

To identify novel host factors that can influence cellular interactions with the SARS-CoV-2 Spike protein, we used a whole genome CRISPR activation approach. Using the Calabrese Human CRISPR Activation Pooled Library (Sanson et al., 2018), we identified a TLR-related cell surface receptor named leucine-rich repeat-containing protein 15 (LRRC15) as a novel SARS-CoV-2 Spike binding protein in three independent whole genome screens. LRRC15 was confirmed to promote Spike binding via flow cytometry, immunoprecipitation and confocal microscopy. Mechanistically, LRRC15 is not a SARS-CoV-2 entry receptor, instead ectopic LRRC15 expression was sufficient to inhibit SARS-CoV-2 pseudovirus infection and can also suppress live SARS-CoV-2 infection. LRRC15 is primarily expressed in innate immune barriers 
including placenta, skin, and lymphatic tissues as well as perturbed-state tissue fibroblasts. By analysing single cell sequencing data from COVID lung infections, we found fibroblast numbers significantly increase, and collagen-producing fibroblasts are primarily LRRC15 ${ }^{+}$. Importantly, LRRC15 expression can suppress SARS-CoV-2 pseudovirus infection in trans and its expression levels control collagen production in fibroblasts. Overall, we show LRRC15 is a master regulator of SARS-CoV-2 infection outcomes, physically linking SARS-CoV-2 to perturbed-state fibroblasts, collagen production and fibrosis associated with "long-haul" COVID.

\section{Results}

\section{High throughput SARS-CoV-2 Spike binding assay}

Based on a priori knowledge of SARS-CoV-1, ACE2 was rapidly identified as the primary receptor for SARS-CoV-2 Spike protein (Zhou et al., 2020). To investigate other host factors that modulate cellular interactions with SARS-CoV-2 Spike, we employed a pooled CRISPR activation (CRISPRa) screening approach. To this end, we developed a novel cellular flow cytometry-based SARS-CoV-2 Spike binding assay using Alexa Fluor 488-labeled Spike protein (Spike488; Figure 1A). While wild-type HEK293T (WT HEK293T) cells that express low levels of ACE2 show minimal binding to Spike488, when we provided ACE2 cDNA HEK293TACE2 cells exhibited high Spike488 binding activity (Figure 1B). To assess the sensitivity of this assay, we mixed HEK293T-ACE2 and WT HEK293T cells at various ratios and then measured Spike488 binding by flow cytometry. An increase in Spike488-binding cells could be detected when as little as $1 \%$ of the total population was $\mathrm{ACE}^{+}$, indicating that this assay has sufficient sensitivity to enable genome-wide screens (Figure 1C). To perform a pooled CRISPRa screen with this system, we generated a stable HEK293T cell line expressing CRISPRa machinery (MS2-p65-HSF + VP64; HEK293T-CRISPRa) (Figure 1D). We tested HEK293T-CRISPRa clones for the ability to induce ACE2 expression using 3 independent single guide RNAs (sgRNAs) (Horlbeck et al., 2016). We selected Clone 1 for further use, since it induced similar levels of ACE2 expression compared to cDNA overexpression, (Supplementary Figure 1A), and confirmed that CRISPRa induction of ACE2 expression conferred Spike488 binding by flow cytometry (Figure 1E).

\section{CRISPR activation screening for regulators of SARS-CoV-2 Spike binding identifies LRRC15}

Having established the utility of our system, we used the Calabrese Human CRISPR Activation Pooled guide Library (Sanson et al., 2018) to drive CRISPRa-dependent expression of the human genome in HEK293T-CRISPRa cells. Cells were infected with lentivirus-packaged CRISPRa sgRNAs and then selected on puromycin to enrich for transduced cells. Transduced cells were incubated with Spike488 and sorted by FACS to isolate CRISPRa-sgRNA cells with enhanced Spike binding. Overall, pooled CRISPRa-sgRNA cells showed more Spike binding than mocktransduced controls (Supplementary Figure 1C). Genomic DNA (gDNA) was collected from unselected or Spike488-selected cells and sgRNA abundance quantified by sequencing (Figure 2A) and then data analyzed using the MAGeCK analysis platform (v0.5.9) (Li et al., 2014) and plotted using MAGeCKFlute (v1.12.0) (Wang et al., 2019). Using an FDR cut off of 0.25, our top hit was the transmembrane protein LRRC15 (LogFC 4.748, P value 2.62 $10^{-7}$, FDR 0.00495 ), followed by the SARS-CoV-2 entry receptor ACE2 (LogFC 2.1343, P value 2.65 $\times 10^{-5}$, 
133 FDR 0.25). (Figure 2B-D; Supplementary Table 1). Moreover, we conducted 2 additional 134 screens under slightly different conditions, and in all screens our top hit was LRRC15 135 (Supplementary Figure 2A-F).

136

137

138

139

140

141

142

143

144

145

146

147

148

149

150

151

152

153

154

155

156

157

158

159

160

161

162

163

164

165

166

167

168

169

170

171

172

173

174

175

176

177

178

We expressed the LRRC15 sgRNAs that were hits in our screens in HEK293T-CRISPRa cells and confirmed that they induce expression of LRRC15 ( approximately 2000 fold induction, Supplementary Figure 2G). Moreover, LRRC15-overexpressing cells dramatically increased SARS-CoV-2 Spike488 binding, with LRRC15 sgRNA 1 inducing binding to levels comparable to cells overexpressing ACE2 sgRNA3 (Figure 2E). LRRC15 overexpression did not itself upregulate $A C E 2$ transcription, suggesting the increased Spike binding in LRRC15-expressing cells is independent of ACE2 upregulation (Supplementary Figure 2H). Conversely, only one of the three ACE2 sgRNAs from the Calabrese library efficiently activated ACE2 expression (Supplementary Figure 2I-J), explaining why ACE2 itself was not a higher ranked hit in our 3 CRISPRa screens (Figure 2D, Supplementary Figure 2A-F). To avoid spectral overlap with GFP-expressing cell lines we conjugated Spike with Alexa Fluor 647 (Spike647), which was used for the rest of the study. Using ACE2 sgRNA3 and LRRC15 sgRNA1 cells, we measured $14.6 \mathrm{nM}$ affinity for ACE2/Spike647, which is similar to previous estimates (range: 4.7 - 133.3 nM (Lan et al., 2020; Wang et al., 2020; Wrapp et al., 2020)) and $70.4 \mathrm{nM}$ for LRRC15/Spike647 (Figure 2F).

\section{LRRC15 is a new transmembrane SARS-CoV-2 Spike interacting protein}

LRRC15 is a 581 amino acid (a.a.) leucine-rich repeat (LRR) protein with 15 extracellular LRRs followed by a single transmembrane domain and a short 22 a.a. intracellular domain (Figure 3A and 3B). LRRC15 belongs to the LRR Tollkin subfamily that includes TLR1-13 and is most closely related to the platelet von Willebrand factor receptor subunit Glycoprotein V (GP5) (Dolan et al., 2007) (Figure 3C, full tree in Supplementary Figure 3A). To confirm a role for LRRC15 in SARS-CoV-2 Spike binding and ensure the interaction was not an artifact of our CRISPRa strategy, we transfected LRRC15-GFP cDNA into HEK293T cells and observed Spike647 binding by flow cytometry. There are two reported isoforms of LRRC15 (LRRC15_1 and LRRC15_2), with LRRC15_1 having 6 additional amino acids at the N-terminus. Although cells transfected with GFP alone showed no binding to Spike647, cells expressing LRRC15 isoform 1 or 2 both showed strong Spike binding (Figure 3D). While LRRC15-dependent Spike binding was higher than cells stably expressing ACE2 (62.1\% and 64.5\% vs. 48.8\%), coexpression of LRRC15 with ACE2 was additive resulting in 86.3\% positive (LRRC15_1) or $83.8 \%$ positive (LRRC15_2) cells (Figure 3E). Interestingly, all cells (100\%) stably expressing ACE2 and TMPRSS2 bound Spike647 regardless of LRRC15 expression (Figure 3F). However, LRRC15 expression in HEK293T-ACE2-TMPRSS2 cells still enhanced the amount of cell surface Spike647 bound by each cell as measured by mean fluorescence intensity (Figure 3G). Moreover, both LRRC15 isoforms colocalized with Spike647 (Figure 3H). To independently confirm an interaction between LRRC15 and SARS-CoV-2 Spike protein, we added Spike to LRRC15-expressing cells and then immunoprecipitated LRRC15. While control GFP transfected HEK293T cells did not show any signal at the size predicted for Spike ( 200 kDa, (Hsieh et al., 2020)) (Supplementary Figure 3B-C), when we expressed and then pulled down either LRRC15_1 or LRRC15_2, in both cases we co-immunoprecipitated Spike protein in the eluate (Figure 3I). Taken together, these data show that LRRC15 expression is sufficient to confer 
SARS-CoV-2 Spike binding to HEK293T cells, and LRRC15 can further enhance Spike interactions in the presence of ACE2 and TMPRSS2.

LRRC15 is not a SARS-CoV-2 entry receptor but can suppress Spike-mediated entry and live virus infection

We next asked if LRRC15 can act as a receptor for SARS-CoV-2 and mediate viral entry. For this we used a SARS-CoV-2 pseudotyped lentivirus system (SARS-CoV-2 pseudovirus) that displays the SARS-CoV-2 Spike protein and carries a luciferase reporter (Figure 4A, Supplementary Figure 4A). Surprisingly, LRRC15 did not confer SARS-CoV-2 pseudovirus tropism in minimally infectable HEK293T cells (Figure 4B). We then tested if LRRC15 expression impacted infection of HEK293T cells expressing ACE2 and TMPRSS2 (Figure 4C, HEK293T-ACE2 cells shown in Supplementary Figure 4B-C), which are highly sensitive to live SARS-CoV-2 infection. Indeed, compared to transfected controls, LRRC15-expressing HEK293T-ACE2-TMPRSS2 cells show a strong ability to suppress SARS-CoV-2 pseudovirus infection, ranging from 56\% suppression of infection at the lowest viral dose (2x10 $\square$ particles) to $24 \%$ suppression at the highest viral dose (5x10 $\square$ particles) (Figure 4C). Next we tested if LRRC15 expression can also suppress viral replication and cytopathic effect in a live SARSCoV-2 infection system. HEK293T-ACE2-TMPRSS2 cells were infected with increasing doses of SARS-CoV-2 (D614G and Delta variants, Figure 4D) and cell death was assessed $48 \mathrm{~h}$ later. Ectopic expression of LRRC15 significantly inhibited D614G infection (two-way ANOVA, $\mathrm{p}<0.05$ ) but not the Delta variant (Figure 4E and 4F). Together, these data show that LRRC15 is not sufficient to confer SARS-CoV-2 tropism and instead can act to reduce SARS-CoV-2 infection.

At the tissue level, LRRC15 RNA is most abundant in the placenta, with expression also found in skin, tongue, tonsils, and lung (Uhlén et al., 2015). At the single cell level, we used the COVID19 Cell Atlas data set to confirm LRRC15 expression in placenta decidua stromal cells (VentoTormo et al., 2018), multiple lymphatic vessels (Huang et al., 2021; Madissoon et al., 2019; Martin et al., 2019; Park et al., 2020), and fibroblasts from the skin (Solé-Boldo et al., 2020), prostate (Henry et al., 2018) and lung (Bharat et al., 2020; Buechler et al., 2021; Delorey et al., 2021; Madissoon et al., 2019; Melms et al., 2021; Vieira Braga et al., 2019) (Figure 5A). In the lung (Melms et al., 2021) (Figure 5B) we found LRRC15 is primarily expressed in fibroblasts as well as a population annotated as "neuronal cells" (Figure 5C), and these populations were not infected with SARS-CoV-2 (Figure 5D). These data were corroborated by two other COVID-19 patient single cell/nucleus RNAseq data sets that show similar LRRC15 fibroblast expression profiles (Supplementary Figure 5A-F), which were also not infected (Delorey et al., 2021) (Supplementary Figure 5C). Together, these data support our in vitro observations that LRRC15 does not mediate SARS-CoV-2 infection but may instead act as an innate immune barrier. In contrast, ACE2 was detected primarily in uninfected type I (AT1) and (AT2) alveolar epithelium (Figure 5D), and SARS-CoV-2-infected alveolar epithelium ("Other epithelial cells") that lost AT1/2 markers and upregulated ribosomal transcripts consistent with viral infection and cell death. 
As single cell data showed an absence of SARS-CoV-2 mRNA in LRRC15 $5^{+}$fibroblasts, we next tested infectivity of lung fibroblasts (IMR90) with SARS-CoV-2 pseudovirus. IMR90 fibroblasts express LRRC15 endogenously (Supplementary Figure 5G) and possess a low level of intrinsic SARS-CoV-2 Spike binding activity (Supplementary Figure 5H). Endogenous LRRC15 expression was confirmed via Western blot (Supplementary Figure 6A-B). Transfection of LRRC15-GFP cDNA in these fibroblasts further enhanced Spike binding capacity (Figure 5E). However, similar to WT HEK293T cells, ectopic expression of LRRC15 was not sufficient to confer SARS-CoV-2 pseudovirus tropism (Figure 5F), confirming that LRRC15 is not a SARSCoV-2 entry receptor. Since $L R R C 15$ and $A C E 2$ expression are mutually exclusive in the lung, we next investigated whether LRRC $15^{+}$fibroblasts could act in trans to sequester SARS-CoV-2 pseudovirus and suppress infection of the highly permissive HEK293T-ACE2-TMPRSS2 line. Indeed, co-incubating permissive HEK293T-ACE2-TMPRSS2 cells with $L R R C 15^{+}$fibroblasts could suppress SARS-CoV-2 pseudovirus transduction (Figure 5G). Thus, LRRC15 is expressed on lung fibroblasts where it can bind SARS-CoV-2 spike and help sequester virus from ACE2expressing SARS-CoV-2 target cells.

\section{LRRC15 is a key regulator of collagen expression}

Pulmonary fibrosis, driven by fibroblasts, is a hallmark of COVID-19, especially in patients with "long-haul" disease (George et al., 2020; Rendeiro et al., 2021). To explore the drivers of fibrosis, we examined single cell datasets from the lungs of control vs COVID-19 patients (Bharat et al., 2020; Delorey et al., 2021; Melms et al., 2021), and found a significant increase in the proportion of fibroblasts in COVID-19 lungs (7.9\% in control and $22.9 \%$ in COVID-19 patients, Figure 6A). A recent study on the organization of tissue fibroblasts identified LRRC15 as a lineage marker for perturbed state activated myofibroblasts (Buechler et al., 2021). These specialized fibroblasts arise during disease, express collagen and other ECM-modifying genes, and participate in tissue repair and fibrosis (Buechler et al., 2021). We also observed lung LRRC $15^{+}$myofibroblasts in multiple COVID-19 patient data sets, and these cells express collagen (Figure 6B). LRRC15 is upregulated in response to proinflammatory cytokines like IL1 $\beta$, IL6, and TNF $\square$ (Satoh et al., 2002), and TGF $\beta$ also upregulates LRRC15 (Figure 6C) and COL1A1 transcripts (Figure 6D). Together, LRRC15 is expressed on collagen producing fibroblasts both in vitro and in the lung of COVID-19 patients and may regulate lung fibrosis.

To directly investigate the relationship between LRRC15 and collagen, we expressed low (Lo) or high (Hi) levels of LRRC15 in fibroblasts (or provided GFP as a transfection control) and then evaluated COL1A1 expression (Figure 6E). Surprisingly, Lo LRRC15 promoted COL1A1 expression while Hi LRRC15 did not (Figure 6F). This bimodal regulation was confirmed with Western blotting (Figure 6G, quantified in H-I, full blots in Supplementary Figure 6). When taken together, our working model is that LRRC15 expression is induced by inflammatory cytokines in COVID-19 lung fibroblasts, where it acts as an innate antiviral barrier that can sequester SARS-CoV-2 and decrease infection. As infection resolves, and the proinflammatory context of the lung changes, LRRC15 expression would reduce, and this would then switch LRRC15 ${ }^{+}$fibroblasts from antiviral role to instead promote lung repair (Figure 6J). Overall, we describe the TLR-related receptor LRRC15 as a master regulator of SARS-CoV-2 infection, with the ability to gauge lung context and physically suppress SARS-CoV-2 infection or promote lung 
repair. We propose that dysregulation of this novel feedback system may play a role in the intense lung fibrosis observed in "long-haul" COVID-19 patients.

\section{Discussion}

Using an unbiased functional genomics approach, we have identified the leucine rich repeat receptor, LRRC15 as a master regulator of SARS-CoV-2 infection and lung repair. LRRC15 promotes SARS-CoV-2 spike binding comparable to ACE2, however this receptor is not sufficient to confer viral tropism. LRRC15 is normally highly expressed in the placenta, skin, and various lymphatics, and is related to TLR innate immune receptors. In previous work, LRRC15 has been shown to suppress adenovirus infection (O'Prey et al., 2008), and here we show LRRC15 can also suppress SARS-CoV-2 Spike pseudovirus and live SARS-CoV-2 infection. Given the expression pattern and function of LRRC15, we hypothesize that this molecule may comprise a new cellular innate immune barrier that is critical for host defense. Importantly, LRRC15 is found on collagen-producing myofibroblasts where it regulates collagen production, directly linking SARS-CoV-2 with the development of lung fibrosis seen in "longhaul" COVID-19.

LRRC15 was initially identified as a factor induced by pro-inflammatory cytokines that would be present in the lungs of COVID-19 patients (Satoh et al., 2002). LRRC15 is a member of the LRR superfamily and LRR-Tollkin subfamily of LRR-containing proteins, many of which play critical roles in host defense (Dolan et al., 2007). Of the TLR family, LRRC15 is most related to TLR5, which also recognises a major extracellular virulence factor, the bacterial extracellular protein flagellin (Hayashi et al., 2001). Remarkably, while this manuscript was in preparation, Shilts et al. released a preprint describing a similar CRISPR activation strategy to identify new host factors that can regulate Spike binding; their screen also pulled out LRRC15 as a top factor driving Spike/host cell interactions (Shilts et al., 2021). This study corroborates our findings, despite their use of different Spike formulations, CRISPRa machinery, and cell lines. Together, these studies highlight a fundamental new role for LRRC15 in SARS-CoV-2 biology.

Several CRISPR Loss of Function (LOF) and Gain of Function (GOF) screens have been reported in attempts to identify novel SARS-CoV-2 interactors and regulators. Though these CRISPR screens have been successful in identifying novel SARS-CoV-2 receptors and coreceptors (Baggen et al., 2021; Goujon et al., 2021; Schneider et al., 2021; Wang et al., 2021; Zhu et al., 2021), ACE2-regulators (Daniloski et al., 2021; Wei et al., 2021), complexes such as the vacuolar ATPase proton pump, Retromer, Commander and SWI/SNF chromatin remodeling machinery (Daniloski et al., 2021; Wei et al., 2021) implicating many new pathways in SARSCoV-2 infection (Daniloski et al., 2021; Schneider et al., 2021; Wang et al., 2021), they have all failed to identify LRRC15. This difference is likely due to SARS-CoV-2 live virus and pseudovirus screens being unable to divorce Spike binding from downstream effects of infection. Our fluorophore-conjugated Spike protein/pooled CRISPR screening model thus represents a new paradigm for investigating host/virus interactions independent of virion entry or cell death.

Although our data shows that LRRC15 promotes cellular binding to SARS-CoV-2 Spike protein, we also show that LRRC15 does not act as an entry receptor, but instead inhibits SARS-CoV-2 
pseudotyped lentivirus infection. This observation is consistent with a report that LRRC15 can also impede adenovirus infection (O'Prey et al., 2008). When we tested live SARS-CoV-2 strains we also observed a significant anti-SARS-CoV-2 activity for LRRC15, although LRRC15 was much more effective against the D614G vs. the Delta variant. We hypothesize that LRRC15 may play a role in limiting SARS-CoV-2 transmission by sequestering free virus in the airways of COVID-19 patients, and the Delta variant has adapted to reduce this effect allowing for higher transmission.

While our data highlights a new role for LRRC15 in promoting SARS-CoV-2 Spike binding, limiting infection, and regulating collagen expression, it is currently unclear how LRRC15 contributes to human COVID-19 disease. We consider multiple possible mechanisms. In vivo, LRRC15 may provide an innate barrier that can slow infection or limit transmission, allowing additional innate mechanisms to clear SARS-CoV-2. For example, LRRC15 could mediate a Tetherin-like function to anchor exiting viral particles to limit spread of the virus through the tissue (Neil et al., 2008). Since in the lung LRRC15 is found in ACE2 negative cells, LRRC15 could primarily act to physically sequester SARS-CoV-2 virions away from permissive cells. Alternatively, the level of LRRC15 expression could control how lung or other tissue fibroblasts react to infection. We found LRRC15 is regulated by TGF $\beta$, and others have reported LRRC15 is upregulated by proinflammatory cytokines including TNF $\alpha$, IL-1 $\beta$ and IFN $\gamma$ (Satoh et al., 2002). Thus, under conditions of appropriate inflammation, LRRC15 may be upregulated and play a primary role in immobilizing and sequestering viral particles to control infection while also suppressing lung fibrosis. LRRC15 may even help fibroblasts pass immobilized virus to innate lung antigen presenting cells, and a recently published spatial-resolution single cell analysis of the lung in COVID-19 showed that lung fibroblasts interact with SARS-CoV-2 Spike+ macrophages and dendritic cells (Rendeiro et al., 2021). Then when inflammation subsides, LRRC15 levels decrease, and lower levels of LRRC15 then promote collagen deposition supporting lung repair. When this system is dysregulated, for example in conditions of chronic lung infection, LRRC15 levels may drop during infection, with inappropriate collagen production then leading to "long- haul" COVID.

Our unbiased functional genomic investigation of SARS-CoV-2 Spike/host interactions identified the novel TLR-related receptor LRRC15 as a powerful host factor driving SARS-CoV2 Spike interactions. Further investigation into how LRRC15 contributes to SARS-CoV-2 pathology will help us better understand and treat this and future pandemics.

\section{STAR Methods}

\section{Resource Availability \\ Lead contact}

Further information and requests for resources and reagents should be directed to and will be fulfilled by the lead contact, Graham G. Neely (greg.neely@sydney.edu.au).

360 This study did not generate any new unique reagents.

\section{Materials availability}

\section{Data and code availability}


CRISPR screen raw read counts have been deposited at GSE186475 and are publicly available as of the date of publication. CRISPR screen analysis is shown in Figure 2 and Supplementary Figure S2. CRISPR screen output is deposited in Supplementary Table S1. This paper also analyzes existing publicly available single cell RNA-sequencing data. The accession numbers for these datasets are listed in the Key Resources Table. All data reported in this paper will be shared by the lead contact upon request. This paper does not report original code. Any additional information required to reanalyze the data reported in this paper is available from the lead contact upon request.

\section{Experimental model and subject details}

\section{Cell culture}

HEK293T cells (female; ATCC, CRL-3216, RRID: CVCL_0063) were cultured in Dulbecco's Modified Eagle Medium (ThermoFisher Scientific, Cat \#11995065) with 10\% HyClone Fetal Bovine Serum (Cytiva, SH30084.03) and 1\% Penicillin-Streptomycin (Gibco, 15140122) at $37^{\circ} \mathrm{C}, 5 \% \mathrm{CO}_{2}$ and atmospheric oxygen. IMR90 E6E7 (female) cells were a gift from Anthony Cesare (Children's Medical Research Institute, Sydney, Australia). IMR90 E6E7 were cultured in DMEM (ThermoFisher Scientific, 11995065) supplemented with 10\% HyClone FBS (Cytiva, SH30084.03) and $1 \mathrm{x}$ non-essential amino acids (Gibco, 11140050 ) at $37^{\circ} \mathrm{C}, 3 \% \mathrm{O}_{2}$ and $10 \%$ $\mathrm{CO}_{2}$. Expi293F ${ }^{\mathrm{TM}}$ cells (female; ThermoFisher Scientific, A14527, RRID:CVCL_D615) were cultured in Expi293 ${ }^{\mathrm{TM}}$ Expression Medium (ThermoFisher Scientific, A1435101) with 5\% $\mathrm{CO}_{2}$ and atmospheric $\mathrm{O}_{2}$ at $37^{\circ} \mathrm{C}$ for $24 \mathrm{~h}$ and then lowered to $32{ }^{\circ} \mathrm{C}$ for $72 \mathrm{~h}$. Cell lines have been authenticated.

\section{Method Details}

\section{Generation of CRISPR activation cell line}

HEK293T cells were co-transfected with pPBR1R2_EF1aVP64dCas9VP64_T2A_MS2p65HSF1-IRESbsdpA (Addgene \#113341) and the Super PiggyBac Transposase Expression Vector (System Biosciences, PB210PA-1) using Lipofectamine 3000 Transfection Reagent (ThermoFisher Scientific). These cells (HEK293TCRISPRa) were then selected on blasticidin (Merck) at $5 \mu \mathrm{g} / \mathrm{mL}$ for 10 days prior to clonal isolation and expansion.

\section{sgRNA vector cloning}

Single guide RNA (sgRNA) sequences for non-targeting control and ACE2 were taken from the Weissman Human Genome-wide CRISPRa-v2 library (Addgene \#83978). LRRC15 sgRNA sequences and additional ACE2 sgRNA sequences were taken from the Human CRISPR activation pooled library set A (Addgene \#92379). Sense and antisense strands for each sequence were ordered as DNA oligonucleotides (IDT) with 5' overhangs of 5'-CACC-3' on the sense strand oligonucleotide and 5'-AAAC-3' on the antisense strand oligonucleotide. Oligonucleotides were annealed at $4^{\circ} \mathrm{C}$ for $16 \mathrm{~h}$ and pXPR-502 (Addgene \#96923) was digested with Esp3I (ThermoFisher Scientific, ER0451) or BsmBI-v2 (New England Biolabs). sgRNA DNA oligonucleotide duplexes were ligated into the digested pXPR-502 backbone using T4 ligase (New England Biolabs) and incubated at $4^{\circ} \mathrm{C}$ overnight. NEB 10-beta competent $E$. coli (New England Biolabs) were transformed with $100 \mathrm{ng}$ of each sgRNA construct by heat-shock, 
plated onto LB-agar plates (Life Technologies) containing ampicillin (Sigma-Aldrich) and grown at $37^{\circ} \mathrm{C}$. Individual colonies were picked, expanded in Luria broth (Life Technologies) supplemented with ampicillin and amplified constructs were harvested using either ISOLATE II Plasmid Mini Kit (Bioline) or PureYield Plasmid Maxiprep System (Promega Corporation).

\section{Whole genome sgRNA library amplification}

MegaX DH10B T1 ${ }^{\mathrm{R}}$ Electrocomp ${ }^{\mathrm{TM}}$ Cells (ThermoFisher Scientific) were electroporated with $400 \mathrm{ng}$ Human CRISPR activation pooled library set A (Addgene \#92379) and left to recover in Recovery Medium for 1 hour at $37^{\circ} \mathrm{C}$. Cells were then spread on $600 \mathrm{~cm}^{2} \mathrm{LB}$-agar plates supplemented with carbenicillin (Merck) and incubated at $37^{\circ} \mathrm{C}$ for 16 hours. All colonies were scraped, collected and processed using the PureYield Plasmid Maxiprep System (Promega Corporation). The concentration of the plasmid library was determined via Nanodrop (ThermoFisher Scientific).

\section{Lentivirus production and viral transduction}

Lipofectamine 3000 Transfection Reagent (ThermoFisher Scientific) in Opti-MEM Medium (Gibco) was used to co-transfect HEK293T cells with psPAX2 (Addgene \#12260), pCAG-VSVg (Addgene \#35616) and either individual sgRNA constructs ligated into pXPR-502 (Addgene \#96923) or pooled CRISPRa library (Human CRISPR activation pooled library set A, Addgene \#92379) according to the manufacturer's instructions. Cells were incubated with transfection reagents for $16 \mathrm{~h}$ before the media was replaced. Viral media was collected $24 \mathrm{~h}$ later. For individual sgRNA constructs, neat viral media was added to HEK293T-CRISPRa cells with Polybrene Infection / Transfection Reagent (Sigma-Aldrich) at a concentration of $8 \mu \mathrm{g} / \mathrm{mL}$. Viral media was replaced with fresh medium the following day and puromycin dihydrochloride (Gibco) added $24 \mathrm{~h}$ later at a concentration of $1.6 \mu \mathrm{g} / \mathrm{mL}$ for $72 \mathrm{~h}$ selection. For sgRNA library virus, viral media was passed through a $0.45 \mu \mathrm{m}$ filter (Merck Millipore) and concentrated using 100K MWCO Pierce Protein Concentrators (Life Technologies Australia). Concentrated virus was then stored at $-80^{\circ} \mathrm{C}$.

\section{SARS-CoV-2 Spike protein production}

The expression construct for recombinant soluble trimeric SARS-CoV-2 spike protein (residues 1-1208, complete ectodomain) was generously provided by Dr Florian Krammer (Icahn School of Medicine, Mt Sinai). This protein was used for the initial setup of the screen (shown in Figure 1) and in one CRISPRa screen (Screen 2). This construct includes the SARS-CoV-2 spike native signal peptide (residues 1-14) to target the recombinant protein for secretion, stabilising proline substitutions at residues 986 and 987, substitution of the furin cleavage site (residues 682-685) with an inert GSAS sequence, and a C-terminal His6-tag to enable affinity purification.

Soluble trimeric SARS-CoV-2 spike was expressed in EXPI293FTM cells via transient transfection using $25 \mathrm{kDa}$ linear polyethyleneimine (PEI) (Polysciences Inc.). EXPI293FTM cultures were grown at $37^{\circ} \mathrm{C}$, with shaking at $130 \mathrm{rpm}$, to a cell density of $3 \times 10^{6}$ cells $/ \mathrm{mL}$ before transfection with pre-formed SARS-CoV-2 spike plasmid DNA:PEI complexes $(2 \mu \mathrm{g} / \mathrm{mL}$ DNA and $8 \mu \mathrm{g} / \mathrm{mL} \mathrm{PEI}$ ). The transfected cells were incubated at $37^{\circ} \mathrm{C}$ for $24 \mathrm{~h}$ and then at $32^{\circ} \mathrm{C}$ for a further $72 \mathrm{~h}$ before harvesting. Culture medium, containing secreted SARS-CoV-2 spike, was harvested by centrifugation at $4000 \mathrm{~g}$ for $20 \mathrm{~min}$. Supernatants from the centrifugation step were supplemented with $20 \mathrm{mM}$ HEPES ( $\mathrm{pH}$ 8.0) and subjected to immobilised metal affinity 
chromatography (IMAC) by incubation with Ni-NTA agarose pre-equilibrated with a buffer consisting of $20 \mathrm{mM} \mathrm{NaH} \mathrm{PO}_{4}(\mathrm{pH} 8.0), 500 \mathrm{mM} \mathrm{NaCl}$, and $20 \mathrm{mM}$ imidazole. His6-tagged SARS-CoV-2 spike protein was eluted from the Ni-NTA agarose using a buffer comprising 20 $\mathrm{mM} \mathrm{NaH} \mathrm{PO}_{4}$ (pH 7.4), $300 \mathrm{mM} \mathrm{NaCl}$, and $500 \mathrm{mM}$ imidazole. Eluates from affinity chromatography were concentrated and further purified by gel filtration chromatography using a Superdex 200 10/30 GL column (Cytiva) and buffer consisting of $20 \mathrm{mM}$ HEPES (pH 7.5) and $150 \mathrm{mM} \mathrm{NaCl}$. The quality of protein purification was assessed by SDS-PAGE and multiple angle laser light scattering (MALLS).

The expression construct for a more stable variant of soluble trimeric SARS-CoV-2 spike ectodomain protein called "HexaPro" was a gift from Jason McLellan (Addgene, \#154754). This "Hexapro" protein was used in 2 CRISPRa screens (Screen 1 and 3) and in all validation experiments. This construct, in addition to above, includes 6 total stabilising proline substitutions at residues 817, 892, 899, 942, 986 and 987. The protein was expressed, and the culture medium was harvested as above. The supernatant containing the protein was supplemented with $20 \mathrm{mM}$ HEPES pH 8.0 and subjected to IMAC with Ni-NTA as above. The eluate was dialysed to a buffer containing $2 \mathrm{mM}$ Tris ( $\mathrm{pH} 8.0$ ) and $200 \mathrm{mM} \mathrm{NaCl}$ and concentrated to reduce the total volume by a factor of 3 . The sample was passed through a $0.22 \mu \mathrm{m}$ filter and purified by gel filtration chromatography using HiLoad 16/600 Superdex 200 (Cytiva) in a buffer composed of 2 $\mathrm{mM}$ Tris ( $\mathrm{pH} \mathrm{8.0)}$ and $200 \mathrm{mM} \mathrm{NaCl}$. The quality of the protein was assessed by SDS-PAGE and MALLS.

\section{Conjugation of SARS-CoV-2 Spike glycoprotein with fluorophores}

Spike protein was conjugated to Alexa Fluor ${ }^{\mathrm{TM}} 488$ or Alexa Fluor ${ }^{\mathrm{TM}} 647$ using protein labelling kits (Invitrogen) according to manufacturer's instructions. Briefly, $50 \mu \mathrm{L}$ of $1 \mathrm{M}$ sodium bicarbonate was added to $500 \mu \mathrm{l}$ of $2 \mathrm{mg} / \mathrm{mL}$ Spike protein. The solution was then added to room temperature Alexa Fluor ${ }^{\mathrm{TM}} 488$ or 647 reactive dye and stirred for $1 \mathrm{~h}$ at room temperature. Conjugated spike proteins were loaded onto Bio-Rad BioGel P-30 Fine size exclusion purification resin column and eluted via gravity (Alexa Fluor ${ }^{\mathrm{TM}} 488$ ) or centrifugation (Alexa Fluor $^{\mathrm{TM}}$ 647). NanoDrop (ThermoFisher Scientific) was used to determine protein concentration.

\section{Generation of ACE2 and dual ACE2/TMPRSS2 cDNA overexpression cell lines}

HEK293T cells stably expressing human ACE2 (HEK293T-ACE2) were generated by transducing HEK293T cells with a lentivirus expressing ACE2 (Tea et al., 2021). Briefly, ACE2 ORF was cloned into a 3rd generation lentiviral expression vector, pRRLsinPPT.CMV.GFP.WPRE (Follenzi et al., 2004) using Age1/BsrG1 cut sites, thus replacing GFP ORF with $A C E 2$ to create a novel expression plasmid, herein referred to as ppt$A C E 2$. Lentiviral particles expressing ACE2 were produced by co-transfecting ppt-ACE2, a 2nd generation lentiviral packaging construct psPAX2 and VSV-G plasmid pMD2.G (Addgene \#12259) in HEK293T cells by using polyethylenimine as previously described (Aggarwal et al., 2012). Virus supernatant was harvested 72 hours post transfection, pre-cleared of cellular debris and centrifuged at $28,000 \mathrm{xg}$ for 90 minutes at $4{ }^{\circ} \mathrm{C}$ to generate concentrated virus stocks. To transduce HEK293T cells, 10,000 cells per well were seeded in a 96 well tissue culture plate and virus supernatant added in a 2 -fold dilution series. At 72 hours post transduction the surface expression of ACE2 was measured by immunostaining the cells with anti-ACE2 monoclonal antibody (Thermo Fisher Scientific, MA5-32307). Cells showing maximal expression of ACE2 
were then sorted into single cells using BD FACS Aria III cell sorter to generate clonal populations of HEK293T-ACE2 cells.

For generating HEK293T cells expressing both ACE2 and TMPRSS2 (HEK293T-ACE2TMPRSS2), HEK293T-ACE2 cells described above were transduced with lentiviral particles expressing TMPRSS2. To achieve this, $h T M P R S S 2 a$ (synthetic gene fragment; IDT) was cloned into lentiviral expression vector pLVX-IRES-ZsGreen (Clontech) using EcoR1/XhoI restriction sites and lentiviral particles expressing TMPRSS 2 were produced as described above. Lentiviral transductions were then performed on HEK293T-ACE2 cells to generate HEK293T-ACE2TMPRSS 2 cells. Clonal selection led to the identification of a highly permissive clone, HekAT24 (Tea et al., 2021), which was then used in subsequent experiments.

\section{Optimizing a flow cytometry-based assay for determining SARS-CoV-2 Spike binding}

HEK293T-ACE2 cells were dissociated by incubating with TrypLE for $5 \mathrm{~min}$ at $37^{\circ} \mathrm{C}$ and neutralized with DMEM. $10^{6}$ cells were collected, washed with $1 \%$ bovine serum albumin (BSA; Sigma-Aldrich) in Dulbecco's Phosphate Buffered Saline (DPBS; Sigma-Aldrich) and then incubated with increasing concentrations of Alexa Fluor 488-conjugated SARS-CoV-2 spike glycoprotein (Spike488) for $30 \mathrm{~min}$ at $4^{\circ} \mathrm{C}$. The cells were then washed once with DPBS before resuspending in $1 \% \mathrm{BSA}$ in DPBS and analyzed using the Cytek Aurora (Cytek Biosciences). For cell mixing experiments, increasing proportions of HEK293T-ACE2 cells (0\%, 1\%, 20\%, $50 \%, 80 \%$ and $100 \%$ ) were combined with decreasing proportions of wildtype (WT) HEK293T cells $(100 \%, 99 \%, 80 \%, 50 \%, 20 \%, 0 \%)$ to a total of $10^{6}$ cells per sample. These samples were incubated with $50 \mu \mathrm{g} / \mathrm{mL}$ Spike488 as described above and analyzed using the Cytek Aurora (Cytek Biosciences).

To confirm the validity of this assay in detecting binding in cells expressing CRISPRa machinery, a clonal line of HEK293T with stable expression of a plasmid encoding dCas9-VP64 and SAM system helper proteins (pPB-R1R2_EF1aVP64dCas9VP64_T2A_MS2p65HSF1IRESbsdpA) (HEK293T-CRISPRa) was transduced with lentivirus carrying ACE2 sgRNA 1 or non-targeting control sgRNA. These cells were then incubated with Spike488 as previously described and analyzed on the Cytek Aurora (Cytek Biosciences).

\section{CRISPR activation screening}

HEK293T-CRISPRa cells were transduced with concentrated Human CRISPR activation pooled library set A (Addgene \#92379)-carrying lentivirus at a multiplicity of infection (MOI) of approximately 0.5 . Cells were selected on puromycin dihydrochloride (Gibco) at a concentration of $1.6 \mu \mathrm{g} / \mathrm{mL}$ for 3 days (screen 1 and 2$) .3 \times 10^{7}$ cells (>500 cells/guide) were incubated with Spike488 for $30 \mathrm{~min}$ at $4^{\circ} \mathrm{C}$, washed to remove excess spike protein, and sorted for increased Alexa Fluor 488 intensity using the BD FACSMelody Cell Sorter (BD Biosciences). Gates for flow assisted cytometric sorting were set using non-targeting control (NTC) sgRNA-transduced cells as a negative control and ACE2 sgRNA-transduced cells as a positive control, both of which had been incubated with Spike488 under the same conditions as stated previously. Unsorted cells were maintained separately so as to be used as a diversity control. Cells were expanded and $2 \times 10^{6}$ cells were then collected for genomic DNA (gDNA) extraction for sorted samples and $3 \times 10^{7}$ for the unsorted diversity control. Remaining diversity control cells were re-seeded and once again incubated with Spike488 under the same conditions as stated previously (screen 3). These Spike-incubated cells were sorted again but selected on puromycin for eight days prior to 
expansion and collection of $1 \times 10^{7}$ cells from both the sorted cell population and the unsorted diversity control population for gDNA extraction. Gating strategy is shown in Supplementary Figure 1B.

gDNA was extracted from all collected cells using the ISOLATE II Genomic DNA Kit (Bioline). Samples were prepared for NGS via PCR. Genomic DNA ( $25 \mu \mathrm{g}$ for unsorted diversity control samples, $5 \mu \mathrm{g}$ for sorted samples) was added to NEBNext High-Fidelity $2 \mathrm{X}$ PCR Master Mix (New England Biolabs) and $0.4 \mu \mathrm{M}$ P5 staggered primer mix and $0.4 \mu \mathrm{M}$ of P7 indexing primer unique to each sample. PCR cycling conditions and primers were adapted from Sanson et al. (Sanson et al., 2018). Primer sequences can be found in Supplementary Table S3. Briefly, reactions were held at $95^{\circ} \mathrm{C}$ for $1 \mathrm{~min}$, followed by 28 cycles of $94^{\circ} \mathrm{C}$ for $30 \mathrm{~s}, 53^{\circ} \mathrm{C}$ for $30 \mathrm{~s}$ and $72^{\circ} \mathrm{C}$ for $30 \mathrm{~s}$, followed by a final $72^{\circ} \mathrm{C}$ extension step for $10 \mathrm{~min}$. Amplicons were gel extracted and purified using the ISOLATE II PCR \& Gel Kit (Bioline) and the quality and concentration of DNA assessed with the High Sensitivity DNA kit (Agilent Technologies). Samples were then sent to Novogene for next generation sequencing. Raw next generation sequencing reads were then processed using MAGeCK (v0.5.9) (Li et al., 2014) to identify enriched genes. Plots were generated using MAGeCKFlute (v1.12.0) (Wang et al., 2019) Normalized read counts were produced using MAGeCK 'count' function on each pairing of unsorted diversity control and sorted sample. Mean and standard deviation was calculated for each individual sample (i.e. separately for diversity control and sorted sample) and the Z-score calculated using $Z=\frac{x-\mu}{\sigma}$, where $\mathrm{x}$ is the normalized read count for an individual $\operatorname{sgRNA}, \square$ is the mean of all normalized read counts in the sample and $\sigma$ is the standard deviation of all normalized read counts in the sample.

\section{Validation of ACE2 and LRRC15 by CRISPRa}

To validate the function of LRRC15 in binding SARS-CoV-2 spike, clonal HEK293T-CRISPRa cells were transduced with lentivirus carrying ACE2 sgRNAs, LRRC15 sgRNAs or a NTC sgRNA. Cells were selected on $1.6 \mu \mathrm{g} / \mathrm{mL}$ puromycin dihydrochloride (Gibco) for 3 days and then collected for analysis by RT-qPCR and flow cytometry. For validation by flow cytometry, $1 \times 10^{6}$ cells were incubated with $50 \mu \mathrm{g} / \mathrm{mL}$ Spike647 as previously described and then analyzed using the Cytek Aurora (Cytek Biosciences). Binding affinity of ACE2 and LRRC15 were conducted with ACE2 sgRNA3 and LRRC15 sgRNA1 cells with 1, 5, 10, 25, 50 and $100 \mu \mathrm{g} / \mathrm{mL}$ Spike647 (corresponding to 7, 35, 70, 175, 350 and $700 \mathrm{nM}$ ).

\section{RNA extraction and RT-qPCR}

RNA was isolated from cells using the ISOLATE II RNA Mini Kit (Bioline) and concentration was measured by Nanodrop (Thermo Scientific). cDNA was synthesized using the iScript Select cDNA Synthesis Kit (Bio-Rad) according to manufacturer's instructions. Briefly, 500 ng of RNA was added to iScript RT Supermix and nuclease-free water to a final volume of $20 \mu \mathrm{L}$. The assembled reactions were then incubated in a thermocycler as follows: $25^{\circ} \mathrm{C}$ for $5 \mathrm{~min}, 46^{\circ} \mathrm{C}$ for $20 \mathrm{~min}$ and then $95^{\circ} \mathrm{C}$ for $1 \mathrm{~min}$. RT-qPCR was then performed on the cDNA samples using SYBR Select Master Mix (ThermoFisher Scientific) and the LightCycler 480 System (Roche). All primer sequences used are listed in the Key Resources Table. Results were analyzed using the $\Delta \Delta \mathrm{C}_{\mathrm{T}}$ method.

\section{LRRC15 crystal structure prediction}


The predicted crystal structure for LRRC15 was calculated using AlphaFold (v2.0) (Jumper et al., 2021) (https://alphafold.ebi.ac.uk/entry/Q8TF66) and sourced via UniProt (UniProt Consortium, 2021) (https://www.uniprot.org/uniprot/Q8TF66).

\section{LRR Tollkin Phylogenetic Tree}

598 Protein sequences of LRR Tollkin family members (Dolan et al., 2007) were clustered using 599 Clustal Omega (v1.2.2) (Sievers et al., 2011). The phylogenetic (Newick) tree was visualized with MEGA11 (Sievers et al., 2011; Stecher et al., 2020).

\section{Validation of LRRC15 independent of CRISPR activation}

LRRC15-TurboGFP fusion constructs (Origene, RG225990 and RG221437) were used for flow cytometry, immunoprecipitation, signaling and immunocytochemistry experiments while LRRC15-myc-DDK fusion constructs (Origene, RC225990 and RC221437) were utilized for SARS-CoV-2 pseudovirus and SARS-CoV-2 live virus inhibition experiments. LRRC15 transcripts were excised from the LRRC15-TurboGFP and LRRC15-myc-DDK constructs and replaced with multiple cloning site to generate empty vector controls for transfection.

To evaluate the role of LRRC15 in binding SARS-CoV-2 spike glycoprotein independent of CRISPR activation machinery, $2.5 \mu \mathrm{g}$ of plasmids carrying the GFP-tagged LRRC15 cDNA transcript 1 or 2, or empty vector control were transfected into HEK293T, HEK293T-ACE2 and HEK293T-ACE2-TMPRSS2 cells as described above. For each sample, $10^{6}$ cells were collected and incubated with Alexa Fluor 647-conjugated SARS-CoV-2 spike glycoprotein (Spike647) and analyzed using the Cytek Aurora (Cytek Biosciences) as described above.

\section{Immunoprecipitation}

For SARS-CoV-2 spike pulldown, $2 \times 10^{7}$ HEK293T cells transfected with LRRC15-TurboGFP (transcript 1 and 2) or pLJM1-EGFP (Addgene \#19319) were incubated with $50 \mu \mathrm{g} / \mathrm{mL}$ spike hexapro for $30 \mathrm{~min}$ at $4^{\circ} \mathrm{C}$ with rotation. Cells were washed with DPBS (Sigma-Aldrich, D8537) and incubated for $15 \mathrm{~min}$ in lysis buffer (1\% Igepal-CA-630, $5 \mathrm{mM}$ Tris $\mathrm{HCl}(\mathrm{pH} 7.4), 150 \mathrm{mM}$ $\mathrm{NaCl}, 1 \mathrm{mM} \mathrm{MgCl} 2,5 \%$ glycerol, $10 \mathrm{mM} \mathrm{NaF}, 10 \mathrm{mM}$ sodium pyrophosphate, $10 \mathrm{mM}$ sodium orthovanadate, $60 \mathrm{mM} \beta$-Glycerophosphate, 1X complete EDTA-free protease inhibitor (Roche)) on ice. Samples were then sonicated at $90 \%$ amplitude for 30 seconds using the BANDELIN SONOPULS mini20 and spun down at 18,000 g for 10 mins. Concentration of protein samples was determined using BCA assay (ThermoFisher Scientific). $1 \mu \mathrm{g}$ of anti-LRRC15 antibody (Abcam, EPR8188(2)) or rabbit IgG (Covance, CTL-4112) was added to $1 \mathrm{mg}$ protein lysate and incubated at $4{ }^{\circ} \mathrm{C}$ with rotation for $2.5 \mathrm{~h}$ before precipitation with protein $\mathrm{G}$ (ThermoFisher Scientific). Immunoprecipitated proteins were eluted with $0.1 \mathrm{M}$ Tris and 4\% SDC. Input, flowthrough and eluate were mixed with $4 \mathrm{X}$ loading buffer and heated at $95^{\circ} \mathrm{C}$ for $5 \mathrm{~min}$. Samples were loaded into pre-cast polyacrylamide gels (4-20\% gradient, Bio-Rad) and electrophoresed at $90 \mathrm{~V}$ for $1.5 \mathrm{~h}$. Proteins were transferred to $0.45 \mu \mathrm{m}$ nitrocellulose membranes at $100 \mathrm{~V}$ for $1 \mathrm{~h}$. Membranes were blocked in Intercept blocking buffer (LI-COR) for $30 \mathrm{~min}$ at room temperature with gentle agitation. Blocking solution was replaced with primary antibody (Spike, LRRC15) Intercept buffer and membranes incubated overnight at $4{ }^{\circ} \mathrm{C}$ with gentle agitation. Membranes were washed three times with TBST for $5 \mathrm{~min}$ with agitation prior to the incubation of membranes with secondary antibody in Intercept buffer for $2 \mathrm{~h}$ at room temperature. Membranes were washed another three times with TBST and then imaged using the Odyssey CLx (LICOR). 


\section{Confocal imaging}

$13 \mathrm{~mm}$ round coverslips were coated with Matrigel (Corning) diluted in DPBS and incubated for $30 \mathrm{~min}$ at $37^{\circ} \mathrm{C}$. HEK293T cells transfected with LRRC15 cDNA constructs were seeded onto the Matrigel-coated coverslips at a density of 50,000 cells per coverslip. The following day, cells were incubated with Alexa Fluor $^{\mathrm{TM}}$ 647-conjugated SARS-CoV-2 spike protein at a concentration of $10 \mu \mathrm{g} / \mathrm{mL}$ in culture media for $30 \mathrm{~min}$ at $37^{\circ} \mathrm{C}$. The cells were fixed in $4 \%$ paraformaldehyde (PFA) for $20 \mathrm{~min}$ at room temperature, washed 3 times with DPBS. Cells were incubated with Hoechst (1:2000 in DPBS) for 20 minutes, washed 3 times and mounted onto Superfrost plus slides (Fisherbrand) and then imaged using the Leica SP6 confocal microscope at $40 \mathrm{X}$.

\section{SARS-CoV-2 pseudotyped lentivirus production and neutralization assay}

SARS-CoV-2 pseudovirus was produced using a five-component plasmid system. Plasmid encoding the SARS-CoV-2 spike protein with an 18 amino acid truncation of the C-terminus was co-transfected into HEK293T cells with pBCKS(HIV-1SDmCMBeGFP-P2A-luc2pre-IIU), which permits equimolar expression of firefly luciferase and EGFP, and packaging plasmids pHCMVgagpolmllstwhv, pcDNA3.1tat $101 \mathrm{ml}$ and pHCMVRevmlwhvpre. Transfection was carried out using Lipofectamine 3000 Transfection Reagent (ThermoScientific) according to manufacturer's instructions. $16 \mathrm{~h}$ after transfection, a media change was performed. Viral media was collected the following day, passed through a $0.45 \mu \mathrm{m}$ filter and then concentrated using 660 100K MWCO Pierce Protein Concentrators (Life Technologies Australia). Concentrated virus was then stored at $-80^{\circ} \mathrm{C}$. Pseudovirus particle concentrations were determined using the QuickTiter ${ }^{\mathrm{TM}}$ Lentivirus Titer Kit (Cell Biolabs, Inc) under manufacturer conditions.

For infection of cells with SARS-CoV-2 pseudovirus, WT HEK293T, HEK293T-ACE2 and HEK293T-ACE2-TMPRSS2 cells were transfected with cDNA for myc-DDK-tagged LRRC15 transcript 1 , empty myc-DDK construct as a control plasmid. Cells were seeded in 96-well plates, concentrated pseudovirus was added 24 hours later in the presence of $8 \mu \mathrm{g} / \mathrm{ml}$ polybrene. Successful transduction of cells was confirmed by observing GFP expression $48 \mathrm{~h}$ posttranduction. The extent of transduction was quantified with the Steady-Glo Luciferase Assay System (Promega Corporation) according to the manufacturer's instructions. Briefly, plates were allowed to equilibrate to room temperature before $50 \mu \mathrm{L}$ of Steady-Glo reagent was added to each well containing $50 \mu \mathrm{L}$ of cell culture media. Plates were incubated at room temperature for 1 $\mathrm{h}$ to permit cell lysis and luminescence was then measured using a plate reader. Luminescence of the LRRC15 cDNA- and control plasmid-transfected cells was normalized to luminescence values recorded in non-transduced wells for the corresponding cell type.

\section{SARS-CoV-2 live virus infection assays}

For assessing the inhibitory effect of native overexpression of LRRC15, HEK293T-ACE2TMPRSS2 cells were transfected with myc-DDK-tagged LRRC15 transcript 1 plasmid (Origene, RC225990) for transient overexpression, with empty myc-DDK plasmid as a control plasmid. HEK293T-ACE2-TMPRSS2 cells were seeded in 384-well plates at a density of $8 \times 10^{3}$ cells/well in the presence of NucBlue ${ }^{\mathrm{TM}}$ live nuclear dye (Invitrogen, USA) at a final concentration of $2.5 \%$ v/v. The SARS-CoV-2 isolates B.1.319 ("wildtype" D614G virus) and B.1.617.2 (Delta strain) were serially diluted in cell-culture medium and an equal volume was then added to the pre- 
plated and nuclear-stained cells to obtain the desired MOI doses. Viral dilutions were performed in duplicate. Plates were then incubated at $37^{\circ} \mathrm{C}$ for 48 hours before whole wells were imaged with an IN Cell Analyzer HS2500 high-content microscopy system (Cytiva). Nuclei counts were obtained with automated IN Carta Image Analysis Software (Cytiva) to determine the percentage of surviving cells compared to uninfected controls. LRRC15 and control plasmid-transfected cells were normalized to the average cell count of uninfected wells for the corresponding cell type to determine the extent of normalized cell death.

\section{Single cell RNA-sequencing analysis}

LRRC15 expression was first queried on the COVID-19 cell atlas interactive website and summarized in Figure 5A. In depth analysis of lung single cell datasets were conducted on 3 studies (Bharat et al., 2020; Delorey et al., 2021; Melms et al., 2021) with Seurat V4.1.0 (Hao et al., 2021). Two single nucleus RNAseq datasets were downloaded from the Single Cell Portal (Broad Institute, SCP1052 and SCP1219) and one single cell RNAseq dataset from Gene Expression Omnibus (GSE158127). Their accompanying metadata, which includes information such as sample ID, sample status and cluster annotations (cell types), were added to Seurat objects using the 'AddMetaData' function. Read counts were normalized using SCTransform, before reanalysis with the standard Seurat workflow of 'RunPCA,' 'FindNeighbours,' 'FindClusters,' and 'RunUMAP'. Cluster identities were assigned using published cluster annotations and plots were generated with 'DimPlot' and 'DotPlot'. The number of cells in each cluster from each study was then tabulated. 'Subset' was utilized to create new fibroblast only datasets before generating collagen (COL1A1, COL1A2, COL8A1, COL11A1, COL12A1) dotplots for LRRC15-expressing (LRRC15>0, Pos) and non-expressing $(L R R C 15=0, \mathrm{Neg})$ fibroblasts.

\section{Fibroblast infectivity and viral immobilization assay}

LRRC15 expression in IMR90 lung fibroblasts were first compared with HEK293T cells by RTqPCR. These cells were then transfected with empty TurboGFP control and LRRC15-TurboGFP (Lipofectamine LTX with plus reagent (ThermoScientific)). Cells were checked for Spike binding activity by incubation with Spike647 and detection via flow cytometry $24 \mathrm{~h}$ posttransduction. Then, these fibroblasts were infected with SARS-CoV-2 pseudovirus as described above and luciferase luminescence were compared to HEK293T-ACE2-TMPRSS2 cells.

For viral immobilization assay, 6,000 HEK293T-ACE2-TMPRSS2 cells were incubated with 12,000 fibroblasts expressing GFP or LRRC15-GFP and SARS-CoV-2 pseudovirus $\left(5 \times 10^{8}\right.$ particles in polybrene, as described above) for an hour at $37^{\circ} \mathrm{C}$ before seeding in a 96-well plate. Transduction was quantified as described above and luminescence was normalized to GFP controls.

\section{Quantification of collagen production in fibroblast}

$5 \mathrm{ng} / \mathrm{mL}$ of TGF- $\beta$ (R\&D Systems) was added to fibroblasts and incubated for $24 \mathrm{~h}$ before collection for LRRC15 and COL1A1 RT-qPCR. For direct regulation experiments, a total of $1.25 \mu \mathrm{g}$ of plasmid DNA of either LRRC15-TurboGFP fusion construct (Origene, RG225990) or empty TurboGFP control plasmid were transfected into fibroblasts before treatment with spike and $\mathrm{qPCR}$ the following day. $1.25 \mu \mathrm{g}$ empty TurboGFP plasmid were transfected for $0 \mu \mathrm{g}$ LRRC15 cells, $0.3125 \mu \mathrm{g}$ LRRC15 plasmid was mixed with $0.9375 \mu \mathrm{g}$ empty TurboGFP 
plasmid for Lo LRRC15 cell transfection and $1.25 \mu \mathrm{g}$ LRRC15-TurboGFP was transfected for Hi LRRC15 cells. Cells were collected at $72 \mathrm{~h}$ for COL1A1 RT-qPCR and Western blots as described above ( $\alpha$-COL1A1,1:1000; $\alpha$-ACTB,1:5000). Densitometry analysis of LRRC15, COL1A1 and ACTB were performed with ImageJ. Band intensities of LRRC15 and COL1A1 were normalized to ACTB.

\section{Quantification and statistical analysis}

SARS-CoV-2 spike glycoprotein titration experiments were analyzed on GraphPad Prism and fitted with non-linear regression (one site -- specific binding) to identify maximal binding $\left(\mathrm{B}_{\max }\right)$ and dissociation constants $\left(\mathrm{K}_{\mathrm{D}}\right)$. CRISPR activation screen analysis was performed using MAGeCK (v0.5.9) (Li et al., 2014). For each sample, Z-scores were calculated using normalized read counts. All density plots were generated using ggplot2. For SARS-CoV-2 pseudovirus and live virus experiments, data shown reflects 3 independent replicates. For pseudovirus, normalized level of transduction was calculated by dividing luminescence recorded for control and LRRC15-transfected cells by luminescence of non-transduced cells of the same cell line. Similarly, for live virus infection assays, cell death for both control and LRRC15-transfected cells was normalized to uninfected controls. All RT-qPCR results were analyzed using $\Delta \Delta \mathrm{C}_{\mathrm{T}}$ method. For COL1A1 RT-qPCR, COL1A1 expression was normalised to $0 \mu \mathrm{g}$ LRRC15 cells. Significance for SARS-CoV-2 pseudotyped lentivirus and live virus experiments were analyzed with two-way ANOVA with Sidak Multiple Comparisons test. For inflammatory cytokine experiments, LRRC15 RT-qPCR expression was analyzed with Mann-Whitney One-Tailed test normalized to control. Co-culture luminescence was analyzed with Mann-Whitney One-tailed test. COL1A1 RT-qPCR expression in LRRC15 transfected fibroblasts were normalized to control cells and analyzed with Kruskal-Wallis with Dunn's Multiple Comparisons test. Western blot band intensity of COL1A1 and LRRC15 were normalized to ACTB and significance was determined by One-way ANOVA with Dunnett's Multiple Comparisons test.

\section{Acknowledgements}

We thank Novogene for CRISPRa library sequencing, Sydney Informatics Hub (Artemis HPC) for single cell data analysis infrastructure, Sydney Cytometry for flow cytometry and FACS support, the technical and scientific assistance of Sydney Microscopy \& Microanalysis, the University of Sydney node of Microscopy Australia, Dr Megan Steain, Dr Mark Larance, Dr Sean Humphrey, Dr Gang Liu, Dr Phil Hansboro, Dr Tim Newsome and members of the Neely lab for helpful discussions. Figure illustrations were created with BioRender.com.

\section{Funding}

G.N. is funded by the National Health and Medical Research Council (NHMRC) project grants APP1107514, APP1158164, APP1158165, the NSW Ministry of Health, and a philanthropic donation from Dr. John and Anne Chong. L.L. is funded by a Dr. John and Anne Chong Fellowship for Genome Editing and seed funding from the Drug Discovery Initiative at the University of Sydney

\section{Author contributions}

LL, GGN conceived this project. LL, MW, AJC, AOS performed experiments. LL, MW, AJC, AOS, DH, GGN performed data analyses. FC facilitated the generation of CRISPRa clonal cell lines. CLM performed microscopy. MW, CED performed molecular cloning. AA generated 
777 ACE2 and ACE2-TMPRSS2 cell lines. ZH performed RT-qPCR. JKKL, KP, RS, JM produced 778 Spike protein. LL, DH, ST, GGN provided supervision and project administration. LL, MW, 779 DH, GGN wrote the manuscript with contributions from all authors.

780

781

782

\section{Declaration of interests}

783

784 
Figure 1 A sensitive FACS-based SARS-CoV-2 Spike binding assay amenable to high Throughput Screening

(A) Schematic of proposed SARS-CoV-2 Spike binding assay. HEK293T cells with stable integration of ACE2 cDNA for overexpression (HEK293T-ACE2) are incubated with Alexa Fluor 488-conjugated SARS-CoV-2 Spike protein (Spike488). Spike488-binding cells are then detected by flow cytometry.

(B) Representative flow cytometry plots for WT HEK293T and HEK293T-ACE2 incubated with Spike488. See also Supplementary Figure 1B for gating strategy.

(C) Titration of HEK293T-ACE2 (ACE2) cells with WT HEK293T cells. 1\% HEK293T-ACE2 cells showed sufficient difference to baseline non-specific binding, a condition that likely mimics the real screen condition. Histogram summary showing mean fluorescence intensity (MFI) of flowed cells.

(D) Schematic of CRISPR activation (CRISPRa) system used. HEK293T cells express synergistic activation machinery (SAM), which includes VP64-dCas9-VP64 protein and helper proteins MS2, p65 and HSF. When transduced with single guide RNA (sgRNA) plasmids, the assembled CRISPRa complex uses MS2 stem loops to recruit the MS2-p65-HSF transcriptional activators. The sgRNA plasmid also encodes the PCP-p65-HSF complex which is recruited to PP7 aptamers in the sgRNA scaffold.

(E) Representative plot of flow cytometry analysis for a clonal HEK293T-CRISPRa cell line transduced with NTC sgRNA or ACE2 sgRNA (expression confirmation via RT-qPCR in Supplementary Figure 1A).

\section{Figure 2. Whole genome CRISPRa screening identified LRRC15 as a novel SARS-CoV-2} Spike-binding protein.

(A) Schematic of CRISPRa screen for identification of novel SARS-CoV-2 Spike-binding proteins. HEK293T-CRISPRa cells were transduced with a whole genome activation library at MOI $=0.5$ and selected on puromycin. HEK293T-CRISPRa cells incubated with Spike488 were analyzed by FACS and genomic DNA extracted from both sorted cells and unsorted diversity control HEK293-CRISPRa cells. Genomic DNA underwent next generation sequencing for gene enrichment analysis. (B) Ranking of all genes in screen 1 by $\log _{2}$ fold change calculated using MAGeCK and plotted using MAGeCKFlute. See also Supplementary Table S1 indicates $\mathrm{p}$-value $=0.05$. Vertical dotted lines indicate $\log _{2}$ fold changes (LFCs) of -2 and 2. Pvalues and LFCs for all genes are reported in Supplementary Table S1. Plot generated using EnhancedVolcano (v1.10.0) R package.

(D) sgRNA Z-scores for screen 1 unsorted and sorted samples. Density curve for all sgRNA Zscores insample (i.e. sorted or unsorted) is shown in grey. Z-scores for ACE2 sgRNA are indicated by vertical blue lines. Z-scores for LRRC15 sgRNAs are indicated by vertical red lines. (E) Flow cytometry analysis of HEK293T-CRISPRa cells transduced with three independent LRRC15 sgRNAs. HEK293T-ACE2 (ACE2 sgRNA3) cells were used as a positive control and NTC sgRNA-transduced HEK293T-CRISPRa cells were used as a negative control. 
(F) Quantification of Spike647 binding in ACE2 sgRNA3 and LRRC15 sgRNA1 cells via flow cytometry. Dissociation constant $(\mathrm{Kd})$ was calculated by fitting with non-linear regression (one site -- specific binding). glycosylation sites.

(B) Predicted protein structure of LRRC15.

(C) LRRC15 is part of the LRR-Tollkin family of proteins.

(D) Flow cytometry analysis of Alexa Fluor-647 (Spike647) binding in WT HEK293T cells, (E) HEK293T-ACE2 and (F) HEK293T cells with stable expression of both ACE2 cDNA and TMPRSS2 cDNA (HEK293T-ACE2-TMPRSS2). Each cell line was transfected with plasmids encoding cDNA for GFP-tagged LRRC15 (transcript 1 or 2) or with empty GFP vector as negative control plasmid. (G) Histogram summary shows mean fluorescence intensity (MFI) of (D-F). (H)Representative images of interaction between LRRC15-GFP and Alexa Fluor 647-conjugated SARS-CoV-2 HexaPro Spike protein in HEK293T cells. Images were taken at 40x magnification. Green $=$ LRRC15-GFP, Red $=$ Spike647, Blue $=$ Hoechst-stained nuclei. Scale bar $=25 \mu \mathrm{m}$. with GFP-tagged LRRC15 (transcript 1 or 2, LRRC15_1 and LRRC15_2, respectively) incubated with SARS-CoV-2 HexaPro Spike protein were immunoprecipitated using antiLRRC15 primary antibody. Immunoblots were performed for LRRC15 and for SARS-CoV-2 HexaPro spike. $\mathrm{I}=$ input, $\mathrm{FT}$ = flow-through, $\mathrm{E}=$ elute.

\section{Fig 4 LRRC15 suppresses SARS-CoV-2 infection.}

(A) Luciferase assay for quantification of SARS-CoV-2 pseudovirus infection in (B) WT HEK293T (n=4) and (C) HEK293T-ACE2-TMPRSS2 (n=3). Cells were transfected with plasmid encoding LRRC15 transcript 1 or empty vector as a control. Luminescence for LRRC15 cells were normalized to Control cells. Significance was determined by two-way ANOVA, Sidak multiple comparison test; **** $\mathrm{p}<0.0001, * * * \mathrm{p}<0.001, * * \mathrm{p}<0.01,{ }^{*} \mathrm{p}<0.05$. (D) Cell death assay for quantification of D614G SARS-CoV-2 live virus infection in HEK293T-ACE2-TMPRSS2 cells. Cell death was determined via nuclei counts 48 hours after addition of virus. (E,F) Quantification of cell survival after incubation with (E) D614G ( $n=4)$ and (F) Delta (n=3) SARS-CoV-2 live virus. Significance was determined by two-way ANOVA, *p<0.05. datasets.

(B) UMAP plot of lung single nucleus RNAseq dataset (Melms et al).

(C) Feature plot and (D) Dotplot shows LRRC15 is expressed in fibroblasts and neuronal cells. Expression of LRRC15 in fibroblasts is also observed in fibroblasts of separate studies (See Supplementary Figure 5). 
(E) Fibroblasts have intrinsic spike binding ability that can be further enhanced by LRRC15 overexpression. Fibroblasts were transfected with empty vector control or LRRC15 cDNA, and spike binding capacity was quantified via flow cytometry. MFI = Mean Fluorescence Intensity. (F) Fibroblasts do not have innate tropism for SARS-CoV-2 and overexpression of LRRC15 does not mediate infection. Untransfected, GFP and LRRC15-GFP transfected fibroblasts were transduced with $5 \times 10^{8}$ SARS-CoV-2 pseudovirus particles for 24 hours before quantification via luciferase assay. Transduction efficiency (luciferase luminescence) was compared to permissive cell line HEK293T-ACE2-TMPRSS2. (G) LRRC15 expressing fibroblasts reduced SARS-CoV-2 pseudovirus transduction in HEK293T-ACE2-TMPRSS2. Luminescence of $L R R C 15^{+}$co-culture was normalized to control GFP co-culture, and significance was determined by Mann-Whitney One-tailed test, ${ }^{*} \mathrm{p}<0.05$.

Figure 6 LRRC15 controls collagen production.

(A) Pooled analysis of 3 independent studies show increase in fibroblasts proportion in COVID lungs $(7.9 \%$ in control $(n=19)$ and $22.9 \%$ in COVID $(n=47)$; Unpaired test, $p<0.0001)$.

(B) $L R R C 15^{+}$fibroblasts have an enhanced collagen gene signature. Dotplots generated from 3 separate studies. Pos $=L R R C 15^{+}, \mathrm{Neg}=L R R C 15^{-}$. (C,D) TGF $\beta$ increased LRRC15 and COL1A1 in fibroblasts. Quantification of LRRC15 (C) and COL1A1 (D) expression via RT-qPCR. Significance was determined by Mann-Whitney OneTailed test, $* * \mathrm{p}<0.01$. expression in GFP control, Lo LRRC15-GFP and Hi LRRC-GFP fibroblasts via RT-qPCR. $L o$ LRRC15 increased COL1A1 expression. Significance was determined by Kruskal-Wallis with Dunn's Multiple Comparisons test, compared to control GFP, $* \mathrm{p}<0.05$. Western blots of LRRC15 and COL1A1 (F, full blots in Supplementary Figure 6). Intensity of LRRC15 and COL1A1 bands were normalized to their respective $\beta$-ACTIN bands. Significance was determined by One-way ANOVA with Dunnett's Multiple Comparisons test, compared to control GFP, $* * \mathrm{p}<0.01$.

902 (J) Summary schematic of LRRC15's role in COVID. Inflammation increase LRRC15 to immobilize SARS-CoV-2 and regulate collagen production.

\section{6}

\section{Supplementary Figure 1. CRISPR activation screen setup.}

(A) RT-qPCR of ACE2 expression in 3 SAM clonal cell lines transduced with 3 sgRNAs that increase expression of ACE2, and with HEK293T-ACE2 cells. Results calculated using - $\square \square \mathrm{C}_{\mathrm{T}}$ method and normalized to non-targeting control (NTC) sgRNA-transduced HEK293T-CRISPRa cells.

(B) FACS gating strategy. Cells were first gated by forward (FSC) and side scatter (SSC) before filtering for singlets. Spike fluorescence was gated by comparison with non-targeting sgRNA transduced cells. Similar strategy was applied to all flow cytometry experiments.

(C) FACS results for 3 whole genome CRISPRa screens with NTC as negative controls. For screen 1, cells were incubated with Alexa Fluor 488-conjugated SARS-CoV-2 HexaPro Spike (Addgene \#154754) and selected on puromycin for 3 days . For screen 2, cells were incubated with Alexa Fluor 488-conjugated SARS-CoV-2 Spike glycoprotein (residues 1-1208, complete ectodomain; gift from Dr. Florian Krammer) and selected on puromycin for 3 days. For screen 3 , 
918

919

920

921

922

923

924

925

926

927

928

929

930

931

932

933

934

935

936

937

938

939

940

941

942

943

944

945

946

947

948

949

950

951

952

953

954

955

956

957

958

959

960

961

962

963

cells were incubated with Alexa Fluor 488-conjugated SARS-CoV-2 HexaPro spike (Addgene \#15474) and selected on puromycin for 8 days.

\section{Supplementary Figure 2. CRISPR screen analysis and validation.}

(A-B) Gene enrichment analysis of screens 2 (A) and 3 (B) performed using MAGeCK. Horizontal dotted line indicates $\mathrm{p}$-value $=0.05$. Vertical dotted lines indicate $\log 2$ fold changes (LFCs) of -2 and 2. P-values and LFCs for all genes in screens 2 and 3 are reported in Supplementary Table S1. Plots were generated using EnhancedVolcano (v1.10.0) R package. (C-D) Density plot of Z-score (grey) for all sgRNA in (C) screen 2 and (D) screen 3. Blue vertical lines indicate Z-score for ACE2 sgRNAs. Red vertical lines indicate Z-score for LRRC15 sgRNAs. Z-scores calculated as described in methods.

(E) $\log _{2}$ fold changes of all genes in Screen 1 vs. $\log _{2}$ fold changes of all genes in Screen 2 .

(F) $\log _{2}$ fold changes of all genes in Screen 1 vs. $\log _{2}$ fold changes of all genes in Screen 3.

(G) LRRC15 expression of cells in Fig 2E quantified via RT-qPCR.

(H) ACE2 expression was not increased in LRRC15 sgRNA transduced cells (quantified via RTqPCR).

(I) The 3 sgRNAs for ACE2 from the Calabrese library used in our screens were transduced into HEK293T-CRISPRa cells and ACE2 expression was confirmed via qPCR. Only sgRNA3 induced upregulation in $A C E 2$ expression.

(J) Transduced cells in (I) were incubated with Spike647 and analyzed via flow cytometry. Only ACE2 sgRNA3 cells showed a significant increase in Spike647 binding.

\section{Supplementary Fig 3. LRRC15 is related to TLRs and interacts with Spike.}

(A) Full phylogenetic tree of LRR-Tollkin family of proteins (includes fly and worm orthologs).

(B) Co-immunoprecipitation of Spike was observed in LRRC15-GFP (transcripts 1 and 2) and ACE2 expressing cells but not in control GFP WT cells. I = input, FT = flow-through, E = elute. (C) Control rabbit IgG did not immunoprecipitate LRRC15 or Spike.

\section{Supplementary Fig 4. LRRC15 expression inhibits SARS-CoV-2 spike pseudovirus infection in ACE2 expression cells.}

(A) SARS-CoV-2 pseudovirus carrying a firefly luciferase cassette was applied to HEK293T, HEK293T-ACE2 and HEK293T-ACE2-TMPRSS2 cells for 24 hours before luminescence quantification. HEK293T cells were relatively resistant to infection while HEK293T-ACE2 and HEK293T-ACE2-TMPRSS2 expressing cells were infectable.

(B) Pseudovirus added to ACE2-expressing cells in the context of LRRC15. Titration of $15 \times 10^{6}$, $62.5 \times 10^{6}, 250 \times 10^{6}$ and $1000 \times 10^{6}$ lentiviral particles in HEK293T-ACE2 cells transfected with 0, $156.25,312.5,625,1250$ and $2500 \mathrm{ng}$ of $L R R C 15$ plasmid DNA.

(C) Normalized LRRC15-mediated inhibition in HEK293T-ACE2 cells.

\section{Supplementary Fig 5. Single cell/nucleus analysis of different studies corroborates} restricted LRRC15 expression in fibroblasts.

(A) UMAP plot of lung single nucleus RNAseq dataset (Delorey et al).

(B) Feature plot and (C) Dotplot shows LRRC15 is expressed in Delorey et al. fibroblasts.

(D) UMAP plot of lung single nucleus RNAseq dataset (Bharat et al).

(E) Feature plot and (F) Dotplot shows LRRC15 is expressed in Bharat et al. Lymphatic Endothelial cells and various populations of fibroblasts. 
964 (G) IMR90 fibroblasts express LRRC15, quantified via RT-qPCR.

965 (H) These fibroblasts have intrinsic spike binding activity.

966 (I) Fibroblasts do not have intrinsic tropism and LRRC15 is not an entry receptor for SARS-

967 CoV-2 pseudovirus.

968

Supplementary Fig 6. Bimodal regulation of COL1A1 by LRRC15.

(A) Full western blots of LRRC15 and COL1A1 of 3 replicates.

971

972

(B) Densitometry analysis of endogenous LRRC1, normalized to $\beta$-ACTIN.

\section{Supplementary Table 1: CRISPR activation screen MAGeCK outputs.}

Collated output of MAGeCK and MAGeCKFlute pipeline. For each screen, normalized read ReadRRA() function is provided.

\section{Supplementary Table 2: Oligonucleotides for CRISPR activation sgRNA constructs} (Addgene, \#83978) or Calabrese Library Set A (Addgene, \#92379).

\section{Supplementary Table 3: Next Generation Sequencing Primers} activation screen samples. Primers were adapted from adapted from Sanson et al. (Sanson et al., 2018)

\section{Supplementary Table 4: RT-qPCR primer sequences}

990

991 
993 Key Resources Table (KRT)

994

\begin{tabular}{|c|c|c|}
\hline REAGENT or RESOURCE & SOURCE & IDENTIFIER \\
\hline \multicolumn{3}{|l|}{ Antibodies } \\
\hline $\begin{array}{l}\text { ACE2 Recombinant Rabbit Monoclonal Antibody } \\
\text { (SN0754) }\end{array}$ & ThermoFisher Scientific & $\begin{array}{l}\text { MA5-32307 } \\
\text { RRID:AB_2809589 }\end{array}$ \\
\hline beta Actin antibody [AC-15] & Abcam & $\begin{array}{l}\text { ab6276-50ul } \\
\text { RRID:AB_2223210 }\end{array}$ \\
\hline Collagen Type I Polyclonal antibody & Proteintech Group & $\begin{array}{l}\text { 14695-1-AP } \\
\text { RRID:AB_2082037 }\end{array}$ \\
\hline $\begin{array}{l}\text { IRDye® }{ }^{\circledR} 680 \mathrm{RD} \text { Goat anti-Mouse IgG Secondary } \\
\text { Antibody }\end{array}$ & Li-Cor Biosciences & $\begin{array}{l}926-68070 \\
\text { RRID AB_2651128 }\end{array}$ \\
\hline $\begin{array}{l}\text { IRDye }{ }^{\circledR} 800 \mathrm{CW} \text { Goat anti-Rabbit IgG Secondary } \\
\text { Antibody }\end{array}$ & Li-Cor Biosciences & $\begin{array}{l}925-32211 \\
\text { RRID AB_2651127 }\end{array}$ \\
\hline Purified Rabbit Polyclonal Isotype Ctrl Antibody & Covance & $\begin{array}{l}\text { CTL-4112 } \\
\text { RRID:AB_2722735 }\end{array}$ \\
\hline $\begin{array}{l}\text { Recombinant Anti-LRRC15 antibody [EPR8188(2)] } \\
\text { (ab150376) }\end{array}$ & Abcam & ab150376-100ul \\
\hline $\begin{array}{l}\text { SARS-CoV / } \\
\text { antibody [1A9] }\end{array}$ & GeneTex & $\begin{array}{l}\text { GTX632604 } \\
\text { RRID:AB_2864418 }\end{array}$ \\
\hline \multicolumn{3}{|l|}{ Bacterial and virus strains } \\
\hline DH10B Electrocompetent E. coli & $\begin{array}{ll}\text { Life } & \text { Technologies } \\
\text { Australia } & \end{array}$ & C640003 \\
\hline NEB® 10-beta Competent E. coli (High Efficiency) & New England Biolabs & C3019I \\
\hline SARS-CoV-2 B.1.319 (D614G genotype) & Turville lab & NA \\
\hline SARS-CoV-2 B.1.617.2 (Delta strain) & Turville lab & NA \\
\hline \multicolumn{3}{|l|}{ Chemicals, peptides, and recombinant proteins } \\
\hline Ampicillin sodium salt & Sigma-Aldrich & A9518 \\
\hline BamHI-HF & New England Biolabs & R3136S \\
\hline
\end{tabular}




\begin{tabular}{|c|c|c|}
\hline Blasticidin S Hydrochloride & Merck & US1203350-25MG \\
\hline Bovine Serum Albumin & Sigma-Aldrich & A9647 \\
\hline BsmBI-v2 & New England Biolabs & R0739L \\
\hline Carbenicillin & Merck & US169101-3 \\
\hline Dulbecco's Modified Eagle Medium & Thermofisher Scientific & 11995065 \\
\hline Dulbecco's Phosphate Buffered Saline & Sigma-Aldrich & D8537 \\
\hline Dynabeads ${ }^{\mathrm{TM}}$ Protein $\mathrm{G}$ for Immunoprecipitation & ThermoFisher Scientific & $10003 \mathrm{D}$ \\
\hline EDTA-free Protease Inhibitor Cocktail & Roche & 11873580001 \\
\hline Esp3I & New England Biolabs & R0734L \\
\hline Human LRRC15 Protein (ECD, Fc Tag) & Sino Biological & 15786-H02H \\
\hline $\begin{array}{l}\text { HyClone Characterized Fetal Bovine Serum, AU } \\
\text { Origin }\end{array}$ & Cytiva & SH30084.03 \\
\hline Igepal-CA-630 & Sigma-Aldrich & I8896 \\
\hline Intercept (TBS) Blocking Buffer & LI-COR & $927-60001$ \\
\hline iScript Select cDNA Synthesis Kit & Bio-Rad & 1708841 \\
\hline LB Agar, powder (Lennox L agar) & Life Technologies & 22700025 \\
\hline Lipofectamine 3000 Transfection Reagent & ThermoFisher Scientific & L3000075 \\
\hline Lipofectamine $^{\mathrm{TM}}$ LTX with Plus ${ }^{\mathrm{TM}}$ Reagent & ThermoFisher Scientific & 15338100 \\
\hline Luria Broth Base (Miller's LB Broth Base) & Life Technologies & 12795084 \\
\hline Matrigel Matrix hESC-Qualified & Corning & 354277 \\
\hline
\end{tabular}




\begin{tabular}{|c|c|c|}
\hline MluI & New England Biolabs & R0198S \\
\hline NEBNext High Fidelity 2X PCR Master Mix & New England Biolabs & M0541L \\
\hline Ni-NTA agarose & ThermoFisher Scientific & R90115 \\
\hline Non-essential amino acids & Gibco & 11140050 \\
\hline NucBlue Live Ready Probes (Hoechst 33342) & Invitrogen & R37605 \\
\hline Opti-MEM I Reduced Serum Medium & Gibco & 31985070 \\
\hline $\begin{array}{l}\text { Polyethylenimine, Linear, MW 25000, Transfection } \\
\text { Grade (PEI } 25 \mathrm{~K}^{\mathrm{TM}} \text { ) }\end{array}$ & Polysciences Inc. & 23966 \\
\hline Penicillin-Streptomycin & Gibco & 15140122 \\
\hline Polybrene Infection / Transfection Reagent & Sigma-Aldrich & TR-1003 \\
\hline Puromycin dihydrochloride & Gibco & A1113803 \\
\hline Recombinant Human TGF-beta 1 Protein & R\&D Systems & 240-B-002/CF \\
\hline SYBR Select Master Mix & ThermoFisher Scientific & 4472908 \\
\hline T4 ligase & New England Biolabs & M0202L \\
\hline TrypLE Express enzyme (1X), phenol red & Life Technologies & 12605028 \\
\hline \multicolumn{3}{|l|}{ Critical commercial assays } \\
\hline $\begin{array}{l}\text { Agilent High Sensitivity DNA Kit (Chips and } \\
\text { Reagents) For } 110 \text { samples }\end{array}$ & Agilent & $5067-4626$ \\
\hline Alexa Fluor ${ }^{\mathrm{TM}} 488$ protein labelling kit & Invitrogen & A10235 \\
\hline Alexa Fluor ${ }^{\mathrm{TM}} 647$ protein labelling kit & Invitrogen & A20173 \\
\hline Bicinchoninic acid assay & ThermoFisher Scientific & 23225 \\
\hline
\end{tabular}




\begin{tabular}{|c|c|c|}
\hline ISOLATE II Genomic DNA Kit & Bioline & BIO-52067 \\
\hline ISOLATE II PCR \& Gel Kit & Bioline & BIO-52060 \\
\hline ISOLATE II Plasmid Mini Kit & Bioline & BIO-52067 \\
\hline ISOLATE II RNA Mini Kit & Bioline & BIO-52072 \\
\hline PureYield Plasmid Maxiprep System & Promega Corporation & A2393 \\
\hline $\begin{array}{l}\text { QuickTiter }{ }^{\mathrm{TM}} \quad \text { Lentivirus } \\
\text { Associated HIV p24) }\end{array}$ & Cell Biolabs, Inc & VPK-107 \\
\hline Steady-Glo Luciferase Assay System & Promega Corporation & E2520 \\
\hline \multicolumn{3}{|l|}{ Deposited data } \\
\hline $\begin{array}{l}\text { CRISPR activation screen next-generation sequencing } \\
\text { fastq files and processed read counts from MAGeCK }\end{array}$ & This paper & GSE186475 \\
\hline $\begin{array}{l}\text { Lung transplantation for patients with severe COVID- } \\
19\end{array}$ & (Bharat et al., 2020) & GSE158127 \\
\hline $\begin{array}{l}\text { Single nucleus and single cell transcriptomic analysis } \\
\text { of COVID-19 lung samples }\end{array}$ & (Delorey et al., 2021) & SCP1052 \\
\hline A molecular single-cell lung atlas of lethal COVID-19 & (Melms et al., 2021) & SCP1219 \\
\hline \multicolumn{3}{|l|}{ Experimental models: Cell lines } \\
\hline Expi293FTM Cells & ThermoFisher Scientific & $\begin{array}{l}\text { A14527 } \\
\text { RRID:CVCL_D615 }\end{array}$ \\
\hline HEK293T & ATCC & $\begin{array}{l}\text { CRL-3216 } \\
\text { RRID: CVCL_0063 }\end{array}$ \\
\hline HEK293T-ACE2 & (Tea et al., 2021) & NA \\
\hline HEK293T-ACE2-TMPRSS2 & (Tea et al., 2021) & NA \\
\hline IMR90 E6E7 & (Cesare et al., 2013) & NA \\
\hline Oligonucleotides & & \\
\hline
\end{tabular}




\begin{tabular}{|c|c|c|}
\hline $\begin{array}{l}\text { Oligonucleotides for CRISPR activation sgRNA } \\
\text { constructs, see Supplementary Table S2 }\end{array}$ & This study & NA \\
\hline $\begin{array}{l}\text { Next Generation Sequencing } \text { Primers, see } \\
\text { Supplementary Table } \mathbf{S 3}\end{array}$ & $\begin{array}{l}\text { Adapted from Sanson et } \\
\text { al. (Sanson et al., 2018) }\end{array}$ & NA \\
\hline RT-qPCR primers, see Supplementary Table S4 & This study & NA \\
\hline \multicolumn{3}{|l|}{ Recombinant DNA } \\
\hline $\begin{array}{l}\text { Human CRISPR Activation Pooled Library (Calabrese } \\
\text { P65-HSF) }\end{array}$ & (Sanson et al., 2018) & $\begin{array}{l}\text { Addgene } \quad \# 92379 \\
\text { RRID:Addgene_92379 }\end{array}$ \\
\hline $\begin{array}{l}\text { LRRC15 (GFP-tagged) - Human leucine rich repeat } \\
\text { containing } 15 \text { (LRRC15), transcript variant } 1\end{array}$ & Origene Technologies & RG225990 \\
\hline $\begin{array}{l}\text { LRRC15 (GFP-tagged) - Human leucine rich repeat } \\
\text { containing } 15 \text { (LRRC15), transcript variant } 2\end{array}$ & Origene Technologies & RG221437 \\
\hline $\begin{array}{l}\text { LRRC15 (myc-DDK-tagged)-Human leucine rich } \\
\text { repeat containing 15 (LRRC15), transcript variant } 1\end{array}$ & Origene Technologies & RC225990 \\
\hline $\begin{array}{l}\text { LRRC15 (myc-DDK-tagged)-Human leucine rich } \\
\text { repeat containing 15 (LRRC15), transcript variant } 2\end{array}$ & Origene Technologies & RC221437 \\
\hline pBCKS(HIV-1SDmCMBeGFP-P2A-luc2pre-IIU) & (Koldej et al., 2005) & NA \\
\hline pCAG-VSVg & $\begin{array}{l}\text { Arthur Nienhuis \& } \\
\text { Patrick Salmon }\end{array}$ & $\begin{array}{l}\text { Addgene } \quad \# 35616 \\
\text { RRID:Addgene_35616 }\end{array}$ \\
\hline pcDNA3.1tat $101 \mathrm{ml}$ & (Koldej et al., 2005) & NA \\
\hline pHCMVgagpolmllstwhv & (Koldej et al., 2005) & NA \\
\hline pHCMVRevmlwhvpre & (Koldej et al., 2005) & NA \\
\hline pLJM1-EGFP & (Sancak et al., 2008) & $\begin{array}{lr}\text { Addgene } \quad \# 19319 \\
\text { RRID:Addgene_19319 }\end{array}$ \\
\hline pLVX-IRES-ZsGreen1 & Clontech & 632187 \\
\hline pMD2.G & $\begin{array}{l}\text { Trono Lab Packaging } \\
\text { and Envelope Plasmids }\end{array}$ & $\begin{array}{lr}\text { Addgene } \quad \# 12259 \\
\text { RRID:Addgene_12259 }\end{array}$ \\
\hline $\begin{array}{l}\text { pPB- } \\
\text { R1R2_EF1aVP64dCas9VP64_T2A_MS2p65HSF1- } \\
\text { IRESbsdpA }\end{array}$ & (Chong et al., 2018) & $\begin{array}{l}\text { Addgene \#113341 } \\
\text { RRID:Addgene_11334 } \\
1\end{array}$ \\
\hline pRRLsinPPT.CMV.GFP.WPRE & $\begin{array}{l}\text { Trono Lab Misc } \\
\text { Plasmids }\end{array}$ & $\begin{array}{l}\text { Addgene } \# 12252 \\
\text { RRID:Addgene_12252 }\end{array}$ \\
\hline
\end{tabular}




\begin{tabular}{|c|c|c|}
\hline pSARS-CoV-2 Spike_018aa_Lenti & (Hoffmann et al., 2020) & NA \\
\hline psPAX2 & $\begin{array}{l}\text { Trono Lab Packaging } \\
\text { and Envelope Plasmids }\end{array}$ & $\begin{array}{l}\text { Addgene } \# 12260 \\
\text { RRID:Addgene_12260 }\end{array}$ \\
\hline pXPR_502 & (Sanson et al., 2018) & $\begin{array}{l}\text { Addgene } \quad \# 96923 \\
\text { RRID:Addgene_96923 }\end{array}$ \\
\hline SARS-CoV-2 S HexaPro & (Hsieh et al., 2020) & $\begin{array}{l}\text { Addgene \#154754 } \\
\text { RRID:Addgene_15475 } \\
4\end{array}$ \\
\hline $\begin{array}{l}\text { SARS-CoV-2 spike protein (residues 1-1208, } \\
\text { complete ectodomain) }\end{array}$ & $\begin{array}{l}\text { Gift from Dr. Florian } \\
\text { Krammer }\end{array}$ & NA \\
\hline Super PiggyBac Transposase Expression Vector & System Biosciences & PB210PA-1 \\
\hline \multicolumn{3}{|l|}{ Software and algorithms } \\
\hline AlphaFold v2.0 & (Jumper et al., 2021) & $\underline{\underline{\mathrm{uttp} /}}$ \\
\hline Clustal Omega v1.2.2 & (Sievers et al., 2011) & http://www.clustal.org/ \\
\hline EnhancedVolcano v1.10.0 & (Blighe, 2018) & $\begin{array}{l}\text { https://bioconductor.org } \\
\underline{\text { /packages/EnhancedVo }} \\
\underline{\text { lcano/ }}\end{array}$ \\
\hline FlowJo & FlowJo & $\begin{array}{l}\underline{\text { https://www.flowjo.co }} \\
\underline{\text { m/solutions/flowjo/dow }} \\
\underline{\text { nloads }}\end{array}$ \\
\hline GraphPad Prism 9 & GraphPad Software & $\begin{array}{l}\text { https://www.graphpad.c } \\
\text { om/scientific- } \\
\underline{\text { software/prism/ }}\end{array}$ \\
\hline Image Studio & LI-COR & $\frac{\text { https://www.licor.com/ }}{\text { bio/image-studio/ }}$ \\
\hline IN Carta Image Analysis Software & Cytiva & $\begin{array}{l}\underline{\text { https://www.molecular }} \\
\text { devices.com/products/c } \\
\text { ellular-imaging- } \\
\underline{\text { systems/acquisition- }} \\
\text { and-analysis- } \\
\text { software/in-carta- } \\
\text { image-analysis- } \\
\text { software }\end{array}$ \\
\hline MAGeCKFlute v1.12.0 & (Wang et al., 2019) & $\begin{array}{l}\frac{\text { https://www.bioconduct }}{\text { or.org/packages/release }} \\
\text { /bioc/html/MAGeCKFl } \\
\text { ute.html }\end{array}$ \\
\hline
\end{tabular}




\begin{tabular}{|c|c|c|}
\hline MEGA11 & (Stecher et al., 2020) & $\begin{array}{l}\text { http://www.megasoftwa } \\
\text { re.net/ }\end{array}$ \\
\hline $\begin{array}{l}\text { Model-based Analysis of Genome-wide CRISPR/Cas9 } \\
\text { Knockout (MAGeCK; v0.5.9) }\end{array}$ & (Li et al., 2014) & $\begin{array}{l}\text { https://sourceforge.net/ } \\
\text { projects/mageck/ }\end{array}$ \\
\hline Seurat v4.1.0 & (Hao et al., 2021) & $\underline{\text { https://satijalab.org/seur }}$ \\
\hline \multicolumn{3}{|l|}{ Other } \\
\hline 100K MWCO Pierce Protein Concentrators & $\begin{array}{ll}\text { Life } & \text { Technologies } \\
\text { Australia } & \end{array}$ & 88533 \\
\hline $\begin{array}{l}\text { 4-20\% Mini-PROTEAN® } \text { TGX }^{\mathrm{TM}} \text { Precast Protein } \\
\text { Gels, } 15 \text {-well, } 15 \mu 1\end{array}$ & Bio-rad & 4561096 \\
\hline Fisherbrand $^{\mathrm{TM}}$ Superfrost ${ }^{\mathrm{TM}}$ Plus Microscope Slides & Fisherbrand & $22-037-246$ \\
\hline HiLoad® 16/600 Superdex® 200 pg & Cytiva & GE28-9893-35 \\
\hline Superdex® 200 10/300 GL & Cytiva & GE17-5175-01 \\
\hline
\end{tabular}

995

\section{References}

Aggarwal, A., Iemma, T.L., Shih, I., Newsome, T.P., McAllery, S., Cunningham, A.L., and Turville, S.G. (2012). Mobilization of HIV spread by diaphanous 2 dependent filopodia in infected dendritic cells. PLoS Pathog. 8, e1002762.

Baggen, J., Persoons, L., Vanstreels, E., Jansen, S., Van Looveren, D., Boeckx, B., Geudens, V., De Man, J., Jochmans, D., Wauters, J., et al. (2021). Genome-wide CRISPR screening identifies TMEM106B as a proviral host factor for SARS-CoV-2. Nat. Genet. 53, 435-444.

Bharat, A., Querrey, M., Markov, N.S., Kim, S., Kurihara, C., Garza-Castillon, R., Manerikar, A., Shilatifard, A., Tomic, R., Politanska, Y., et al. (2020). Lung transplantation for patients with severe COVID-19. Sci. Transl. Med. 12.

Blighe, K. (2018). EnhancedVolcano (Bioconductor).

Buechler, M.B., Pradhan, R.N., Krishnamurty, A.T., Cox, C., Calviello, A.K., Wang, A.W., Yang, Y.A., Tam, L., Caothien, R., Roose-Girma, M., et al. (2021). Cross-tissue organization of the fibroblast lineage. Nature 593, 575-579. 
1014 Cesare, A.J., Hayashi, M.T., Crabbe, L., and Karlseder, J. (2013). The telomere deprotection 1015 response is functionally distinct from the genomic DNA damage response. Mol. Cell 51, 1411016155.

1017 Chong, Z.-S., Ohnishi, S., Yusa, K., and Wright, G.J. (2018). Pooled extracellular receptor1018 ligand interaction screening using CRISPR activation. Genome Biol. 19, 205.

1019 Daniloski, Z., Jordan, T.X., Wessels, H.-H., Hoagland, D.A., Kasela, S., Legut, M., Maniatis, S., 1020 Mimitou, E.P., Lu, L., Geller, E., et al. (2021). Identification of Required Host Factors for 1021 SARS-CoV-2 Infection in Human Cells. Cell 184, 92-105.e16.

1022 Delorey, T.M., Ziegler, C.G.K., Heimberg, G., Normand, R., Yang, Y., Segerstolpe, Å., 1023 Abbondanza, D., Fleming, S.J., Subramanian, A., Montoro, D.T., et al. (2021). COVID-19 tissue 1024 atlases reveal SARS-CoV-2 pathology and cellular targets. Nature 595, 107-113.

1026

Dolan, J., Walshe, K., Alsbury, S., Hokamp, K., O’Keeffe, S., Okafuji, T., Miller, S.F.C., Tear,

1027 G., and Mitchell, K.J. (2007). The extracellular leucine-rich repeat superfamily; a comparative 1028 survey and analysis of evolutionary relationships and expression patterns. BMC Genomics 8 , 320.

1029 Follenzi, A., Battaglia, M., Lombardo, A., Annoni, A., Roncarolo, M.G., and Naldini, L. (2004). 1030 Targeting lentiviral vector expression to hepatocytes limits transgene-specific immune response and establishes long-term expression of human antihemophilic factor IX in mice. Blood 103, $1032 \quad 3700-3709$.

1033 George, P.M., Wells, A.U., and Jenkins, R.G. (2020). Pulmonary fibrosis and COVID-19: the 1034 potential role for antifibrotic therapy. Lancet Respir Med 8, 807-815.

1035 Goujon, C., Rebendenne, A., Roy, P., Bonaventure, B., Valadao, A.C., Desmarets, L., Rouillé, 1036 Y., Tauziet, M., Arnaud-Arnould, M., Giovannini, D., et al. (2021). Bidirectional genome-wide 1037 CRISPR screens reveal host factors regulating SARS-CoV-2, MERS-CoV and seasonal HCoVs. 1038 Res Sq.

1039 Hao, Y., Hao, S., Andersen-Nissen, E., Mauck, W.M., 3rd, Zheng, S., Butler, A., Lee, M.J., 1040 Wilk, A.J., Darby, C., Zager, M., et al. (2021). Integrated analysis of multimodal single-cell data. 1041 Cell 184, 3573-3587.e29.

1042 Hayashi, F., Smith, K.D., Ozinsky, A., Hawn, T.R., Yi, E.C., Goodlett, D.R., Eng, J.K., Akira, 1043 S., Underhill, D.M., and Aderem, A. (2001). The innate immune response to bacterial flagellin is 1044 mediated by Toll-like receptor 5. Nature 410, 1099-1103.

1045 Henry, G.H., Malewska, A., Joseph, D.B., Malladi, V.S., Lee, J., Torrealba, J., Mauck, R.J., 1046 Gahan, J.C., Raj, G.V., Roehrborn, C.G., et al. (2018). A Cellular Anatomy of the Normal Adult 1047 Human Prostate and Prostatic Urethra. Cell Rep. 25, 3530-3542.e5.

1048 Hoffmann, M., Kleine-Weber, H., and Pöhlmann, S. (2020). A Multibasic Cleavage Site in the 1049 Spike Protein of SARS-CoV-2 Is Essential for Infection of Human Lung Cells. Mol. Cell 78, 1050 779-784.e5. 
1051

1052

1053

1054

1055

1056

1057

1058

1059

1060

1061

1062

1063

1064

1065

1066

1067

1068

1069

1070

1071

1072

1073

1074

1075

1076

1077

1078

1079

1080

1081

1082

1083

1084

1085

1086

1087

Horlbeck, M.A., Gilbert, L.A., Villalta, J.E., Adamson, B., Pak, R.A., Chen, Y., Fields, A.P., Park, C.Y., Corn, J.E., Kampmann, M., et al. (2016). Compact and highly active next-generation libraries for CRISPR-mediated gene repression and activation. Elife 5 .

Hsieh, C.-L., Goldsmith, J.A., Schaub, J.M., DiVenere, A.M., Kuo, H.-C., Javanmardi, K., Le, K.C., Wrapp, D., Lee, A.G., Liu, Y., et al. (2020). Structure-based design of prefusion-stabilized SARS-CoV-2 spikes. Science 369, 1501-1505.

Huang, N., Pérez, P., Kato, T., Mikami, Y., Okuda, K., Gilmore, R.C., Conde, C.D., Gasmi, B., Stein, S., Beach, M., et al. (2021). SARS-CoV-2 infection of the oral cavity and saliva. Nat. Med. 27, 892-903.

Jia, H.P., Look, D.C., Shi, L., Hickey, M., Pewe, L., Netland, J., Farzan, M., Wohlford-Lenane, C., Perlman, S., and McCray, P.B., Jr (2005). ACE2 receptor expression and severe acute respiratory syndrome coronavirus infection depend on differentiation of human airway epithelia. J. Virol. 79, 14614-14621.

Jumper, J., Evans, R., Pritzel, A., Green, T., Figurnov, M., Ronneberger, O., Tunyasuvunakool, K., Bates, R., Žídek, A., Potapenko, A., et al. (2021). Highly accurate protein structure prediction with AlphaFold. Nature 596, 583-589.

Koldej, R., Cmielewski, P., Stocker, A., Parsons, D.W., and Anson, D.S. (2005). Optimisation of a multipartite human immunodeficiency virus based vector system; control of virus infectivity and large-scale production. J. Gene Med. 7, 1390-1399.

Kuba, K., Imai, Y., Rao, S., Gao, H., Guo, F., Guan, B., Huan, Y., Yang, P., Zhang, Y., Deng, W., et al. (2005). A crucial role of angiotensin converting enzyme 2 (ACE2) in SARS coronavirus-induced lung injury. Nat. Med. 11, 875-879.

Lan, J., Ge, J., Yu, J., Shan, S., Zhou, H., Fan, S., Zhang, Q., Shi, X., Wang, Q., Zhang, L., et al. (2020). Structure of the SARS-CoV-2 spike receptor-binding domain bound to the ACE2 receptor. Nature 581, 215-220.

Li, W., Moore, M.J., Vasilieva, N., Sui, J., Wong, S.K., Berne, M.A., Somasundaran, M., Sullivan, J.L., Luzuriaga, K., Greenough, T.C., et al. (2003). Angiotensin-converting enzyme 2 is a functional receptor for the SARS coronavirus. Nature 426, 450-454.

Li, W., Xu, H., Xiao, T., Cong, L., Love, M.I., Zhang, F., Irizarry, R.A., Liu, J.S., Brown, M., and Liu, X.S. (2014). MAGeCK enables robust identification of essential genes from genomescale CRISPR/Cas9 knockout screens. Genome Biol. 15, 554.

Lu, R., Zhao, X., Li, J., Niu, P., Yang, B., Wu, H., Wang, W., Song, H., Huang, B., Zhu, N., et al. (2020). Genomic characterisation and epidemiology of 2019 novel coronavirus: implications for virus origins and receptor binding. Lancet 395, 565-574.

Madissoon, E., Wilbrey-Clark, A., Miragaia, R.J., Saeb-Parsy, K., Mahbubani, K.T., Georgakopoulos, N., Harding, P., Polanski, K., Huang, N., Nowicki-Osuch, K., et al. (2019). scRNA-seq assessment of the human lung, spleen, and esophagus tissue stability after cold 
preservation. Genome Biol. 21, 1 .

1089 Martin, J.C., Chang, C., Boschetti, G., Ungaro, R., Giri, M., Grout, J.A., Gettler, K., Chuang, L.1090 S., Nayar, S., Greenstein, A.J., et al. (2019). Single-Cell Analysis of Crohn's Disease Lesions 1091 Identifies a Pathogenic Cellular Module Associated with Resistance to Anti-TNF Therapy. Cell 178, 1493-1508.e20.

1093

Melms, J.C., Biermann, J., Huang, H., Wang, Y., Nair, A., Tagore, S., Katsyv, I., Rendeiro, A.F., 1094 Amin, A.D., Schapiro, D., et al. (2021). A molecular single-cell lung atlas of lethal COVID-19.

1095 Nature 595, 114-119.

1096 Neil, S.J.D., Zang, T., and Bieniasz, P.D. (2008). Tetherin inhibits retrovirus release and is 1097 antagonized by HIV-1 Vpu. Nature 451, 425-430.

O’Prey, J., Wilkinson, S., and Ryan, K.M. (2008). Tumor antigen LRRC15 impedes adenoviral 1099 infection: implications for virus-based cancer therapy. J. Virol. 82, 5933-5939.

1100 Park, J.-E., Botting, R.A., Domínguez Conde, C., Popescu, D.-M., Lavaert, M., Kunz, D.J., Goh, I., Stephenson, E., Ragazzini, R., Tuck, E., et al. (2020). A cell atlas of human thymic development defines $\mathrm{T}$ cell repertoire formation. Science 367.

1103 Rendeiro, A.F., Ravichandran, H., Bram, Y., Chandar, V., Kim, J., Meydan, C., Park, J., Foox, 1104 J., Hether, T., Warren, S., et al. (2021). The spatial landscape of lung pathology during COVID110519 progression. Nature 593, 564-569.

1106 Sancak, Y., Peterson, T.R., Shaul, Y.D., Lindquist, R.A., Thoreen, C.C., Bar-Peled, L., and 1107 Sabatini, D.M. (2008). The Rag GTPases bind raptor and mediate amino acid signaling to 1108 mTORC1. Science 320, 1496-1501.

1109 Sanson, K.R., Hanna, R.E., Hegde, M., Donovan, K.F., Strand, C., Sullender, M.E., Vaimberg, 1110 E.W., Goodale, A., Root, D.E., Piccioni, F., et al. (2018). Optimized libraries for CRISPR-Cas9 genetic screens with multiple modalities. Nat. Commun. 9, 5416.

1112 Satoh, K., Hata, M., and Yokota, H. (2002). A novel member of the leucine-rich repeat 1113 superfamily induced in rat astrocytes by beta-amyloid. Biochem. Biophys. Res. Commun. 290, $1114756-762$.

1115 Schneider, W.M., Luna, J.M., Hoffmann, H.-H., Sánchez-Rivera, F.J., Leal, A.A., Ashbrook, 1116 A.W., Le Pen, J., Ricardo-Lax, I., Michailidis, E., Peace, A., et al. (2021). Genome-Scale 1117 Identification of SARS-CoV-2 and Pan-coronavirus Host Factor Networks. Cell 184, 1201118 132.e14.

1119 Shilts, J., Crozier, T.W.M., Teixeira-Silva, A., Gabaev, I., Greenwood, E.J.D., Watson, S.J., 1120 Ortmann, B.M., Gawden-Bone, C.M., Pauzaite, T., Hoffmann, M., et al. (2021). LRRC15 1121 mediates an accessory interaction with the SARS-CoV-2 spike protein. bioRxiv 1122 2021.09.25.461776; doi: https://doi.org/10.1101/2021.09.25.461776.

1123 Sievers, F., Wilm, A., Dineen, D., Gibson, T.J., Karplus, K., Li, W., Lopez, R., McWilliam, H., 
1124 Remmert, M., Söding, J., et al. (2011). Fast, scalable generation of high-quality protein multiple sequence alignments using Clustal Omega. Mol. Syst. Biol. 7, 539.

1126 Spandidos, A., Wang, X., Wang, H., and Seed, B. (2010). PrimerBank: a resource of human and mouse PCR primer pairs for gene expression detection and quantification. Nucleic Acids Res.

1128 38, D792-D799.

1129 Solé-Boldo, L., Raddatz, G., Schütz, S., Mallm, J.-P., Rippe, K., Lonsdorf, A.S., Rodríguez-

1130 Paredes, M., and Lyko, F. (2020). Single-cell transcriptomes of the human skin reveal age-

1131 related loss of fibroblast priming. Commun Biol 3, 188.

1132 Stecher, G., Tamura, K., and Kumar, S. (2020). Molecular Evolutionary Genetics Analysis

1133 (MEGA) for macOS. Mol. Biol. Evol. 37, 1237-1239.

1134 Tea, F., Ospina Stella, A., Aggarwal, A., Ross Darley, D., Pilli, D., Vitale, D., Merheb, V., Lee, 1135 F.X.Z., Cunningham, P., Walker, G.J., et al. (2021). SARS-CoV-2 neutralizing antibodies:

1136 Longevity, breadth, and evasion by emerging viral variants. PLoS Med. 18, e1003656.

1137 Uhlén, M., Fagerberg, L., Hallström, B.M., Lindskog, C., Oksvold, P., Mardinoglu, A.,

1138 Sivertsson, Å., Kampf, C., Sjöstedt, E., Asplund, A., et al. (2015). Proteomics. Tissue-based map 1139 of the human proteome. Science $347,1260419$.

1140 UniProt Consortium (2021). UniProt: the universal protein knowledgebase in 2021. Nucleic 1141 Acids Res. 49, D480-D489.

1142 Vento-Tormo, R., Efremova, M., Botting, R.A., Turco, M.Y., Vento-Tormo, M., Meyer, K.B., 1143 Park, J.-E., Stephenson, E., Polański, K., Goncalves, A., et al. (2018). Single-cell reconstruction 1144 of the early maternal-fetal interface in humans. Nature 563, 347-353.

1145 Vieira Braga, F.A., Kar, G., Berg, M., Carpaij, O.A., Polanski, K., Simon, L.M., Brouwer, S., 1146 Gomes, T., Hesse, L., Jiang, J., et al. (2019). A cellular census of human lungs identifies novel 1147 cell states in health and in asthma. Nat. Med. 25, 1153-1163.

1148 Wang, B., Wang, M., Zhang, W., Xiao, T., Chen, C.-H., Wu, A., Wu, F., Traugh, N., Wang, X., $\mathrm{Li}, \mathrm{Z}$., et al. (2019). Integrative analysis of pooled CRISPR genetic screens using MAGeCKFlute. Nat. Protoc. 14, 756-780.

1151 Wang, Q., Zhang, Y., Wu, L., Niu, S., Song, C., Zhang, Z., Lu, G., Qiao, C., Hu, Y., Yuen, K.1152 Y., et al. (2020). Structural and Functional Basis of SARS-CoV-2 Entry by Using Human ACE2. 1153 Cell 181, 894-904.e9.

1154 Wang, R., Simoneau, C.R., Kulsuptrakul, J., Bouhaddou, M., Travisano, K.A., Hayashi, J.M., 1155 Carlson-Stevermer, J., Zengel, J.R., Richards, C.M., Fozouni, P., et al. (2021). Genetic Screens 1156 Identify Host Factors for SARS-CoV-2 and Common Cold Coronaviruses. Cell 184, 1061157 119.e14.

1158 Wang, Y., Liu, Y., Zhang, M., Lv, L., Zhang, X., Zhang, P., and Zhou, Y. (2018). LRRC15 1159 promotes osteogenic differentiation of mesenchymal stem cells by modulating p65 
1160 cytoplasmic/nuclear translocation. Stem Cell Res. Ther. 9, 65.

1161 Wei, J., Alfajaro, M.M., DeWeirdt, P.C., Hanna, R.E., Lu-Culligan, W.J., Cai, W.L., Strine, 1162 M.S., Zhang, S.-M., Graziano, V.R., Schmitz, C.O., et al. (2021). Genome-wide CRISPR 1163 Screens Reveal Host Factors Critical for SARS-CoV-2 Infection. Cell 184, 76-91.e13.

1164 Wrapp, D., Wang, N., Corbett, K.S., Goldsmith, J.A., Hsieh, C.-L., Abiona, O., Graham, B.S., 1165 and McLellan, J.S. (2020). Cryo-EM structure of the 2019-nCoV spike in the prefusion 1166 conformation. Science 367, 1260-1263.

1167 Zhou, P., Yang, X.-L., Wang, X.-G., Hu, B., Zhang, L., Zhang, W., Si, H.-R., Zhu, Y., Li, B., 1168 Huang, C.-L., et al. (2020). A pneumonia outbreak associated with a new coronavirus of 1169 probable bat origin. Nature 579, 270-273.

1170 Zhu, S., Liu, Y., Zhou, Z., Zhang, Z., Xiao, X., Liu, Z., Chen, A., Dong, X., Tian, F., Chen, S., et 1171 al. (2021). Genome-wide CRISPR activation screen identifies candidate receptors for SARS1172 CoV-2 entry. Sci. China Life Sci.

1173

1174

1175

1176

1177

1178

1179 

(which was not certified by peer review) is the authorkitider. All rights reserved. NA GES allowed without permission.

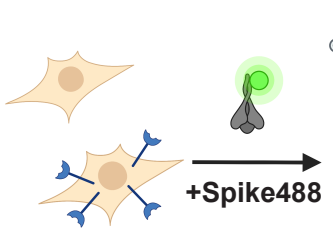

WT or ACE2+

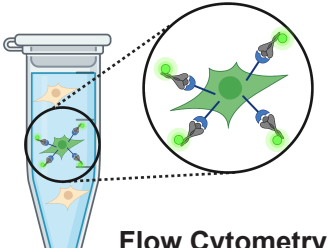

Flow Cytometry

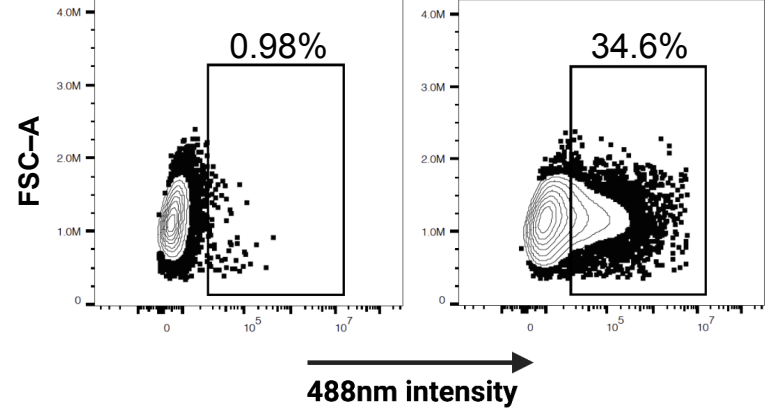

C

$100 \%$ ACE2

$80 \%$ ACE2
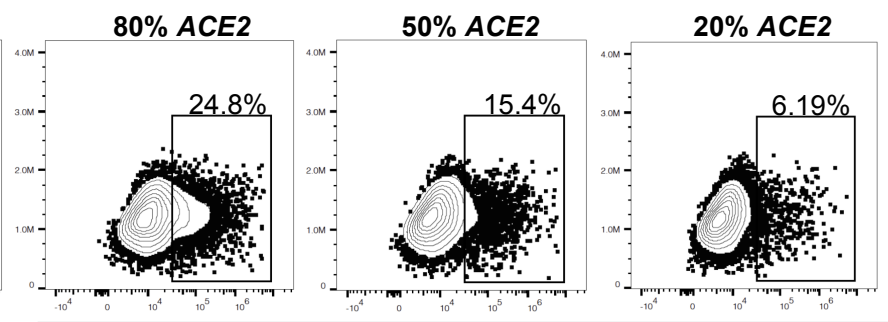

\section{8nm intensity}

D

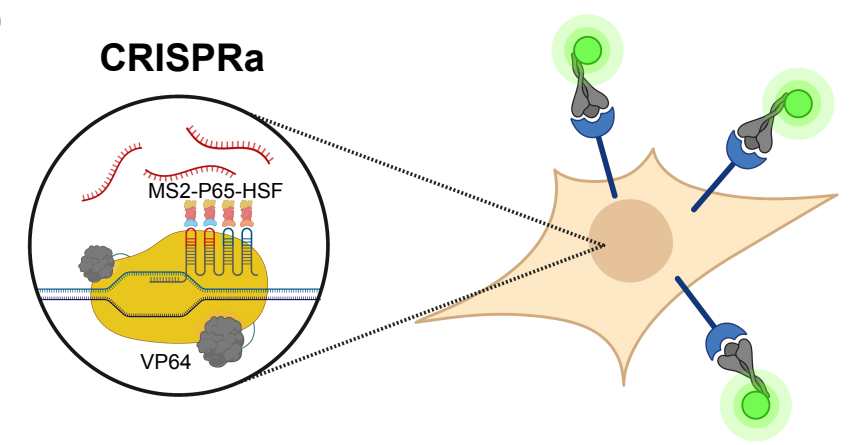

Increased ACE2 expression

Spike binding

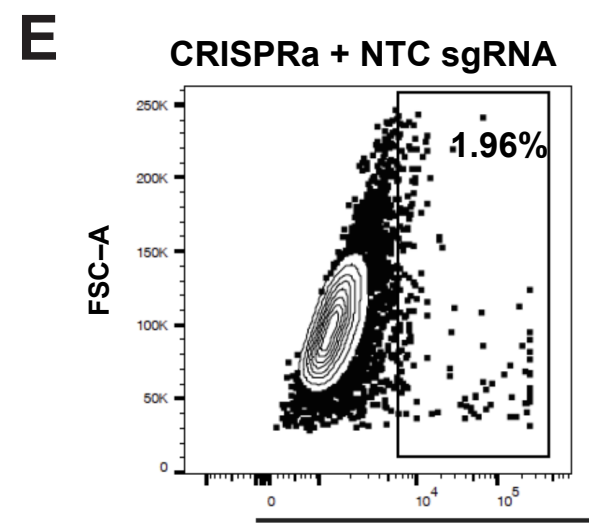

CRISPRa + ACE2 sgRNA

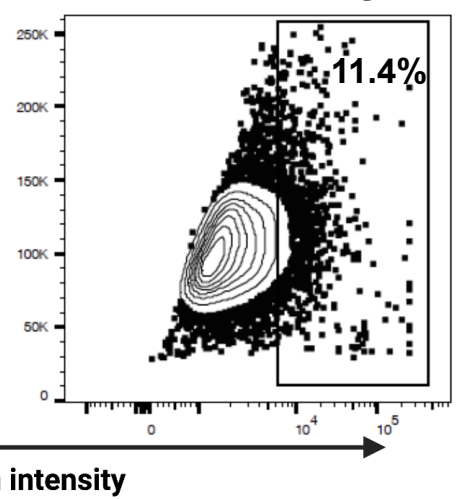

$1 \%$ ACE2

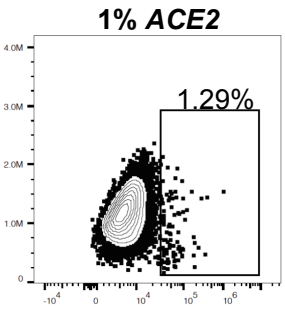

(10)

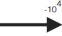

$\longrightarrow$

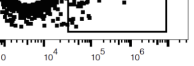

$100: 0$
MFI

87737

47364

21269

8388

7738

\section{$488 \mathrm{~nm}$ intensity}


bioRxiv preprint doi: https://doi.org/10.1101/2021.11.09.467981; this version posted November 10,2021 . The copyright holder for this preprint

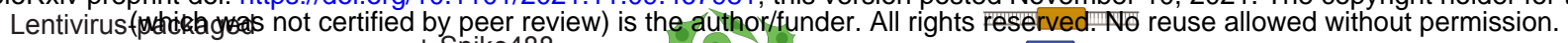
sgRNA library
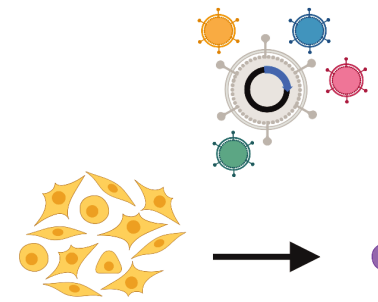

HEK293T-CRISPRa

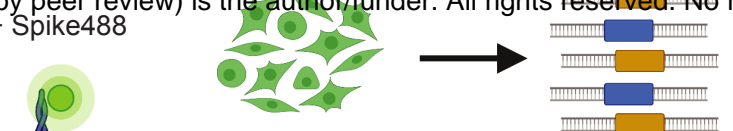

Spike488+ cells

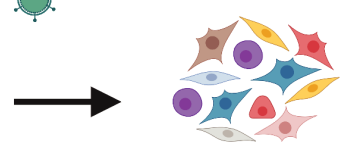

sgRNA library transduced cells

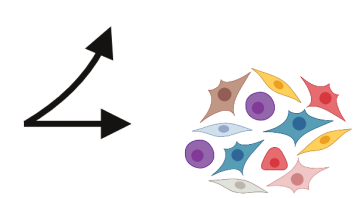

Unsorted cells

Extraction of transgenic sgRNA
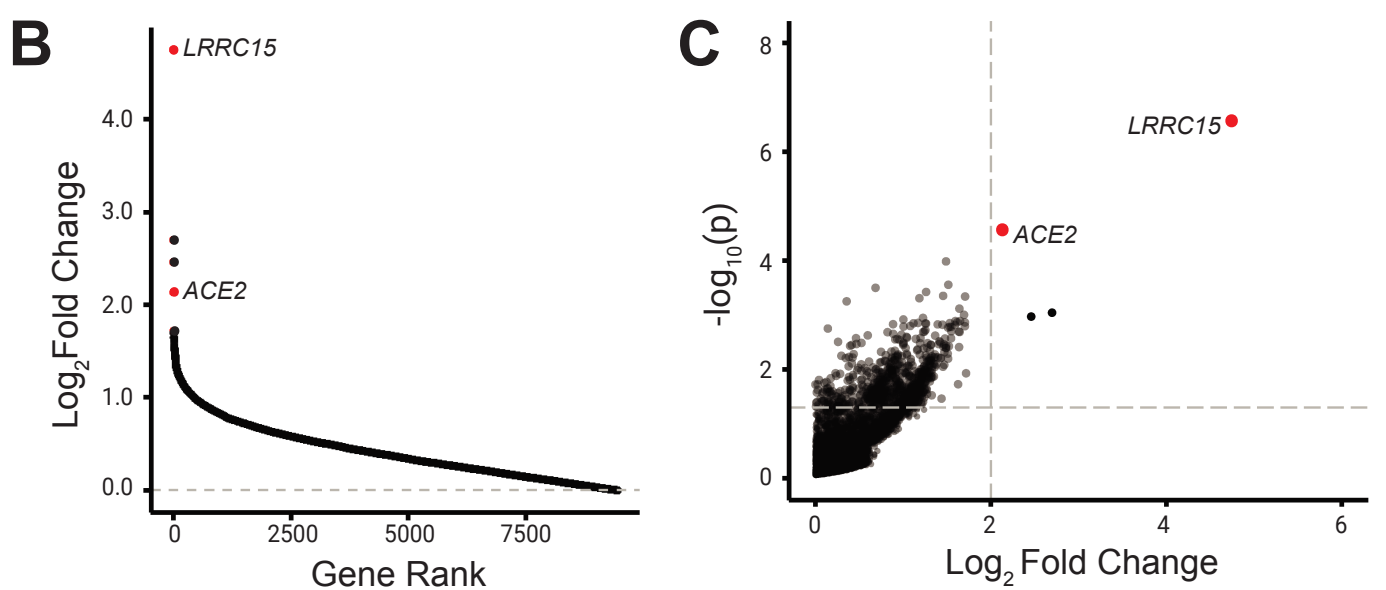
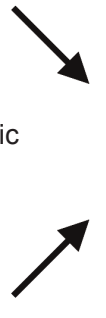

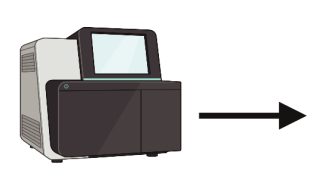

Next generation sequencing
Enrichment of sgRNA inducing Spike488 binding

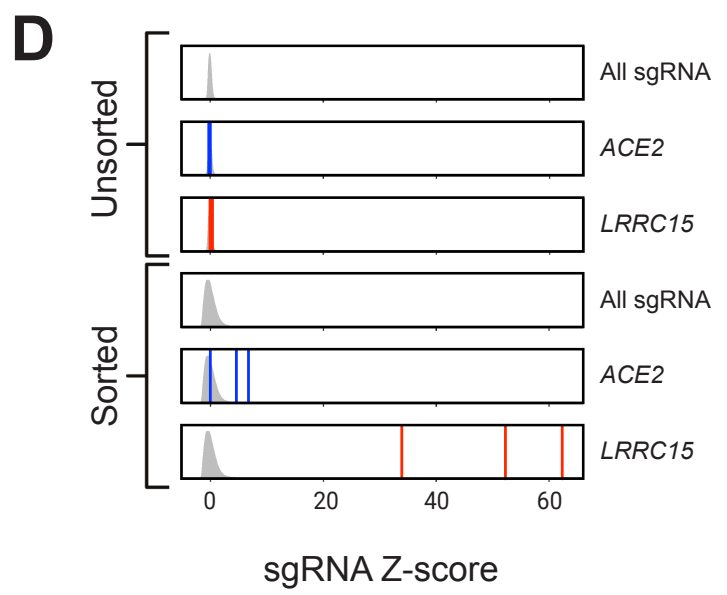

E
NTC

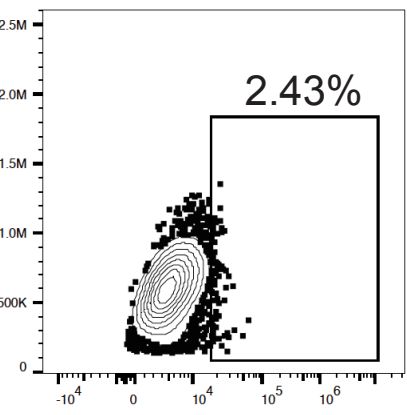

LRRC15 sgRNA1

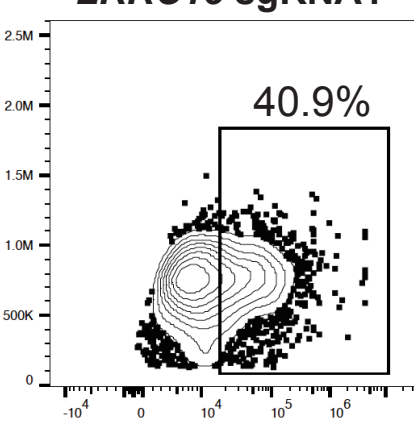

ACE2 sgRNA3
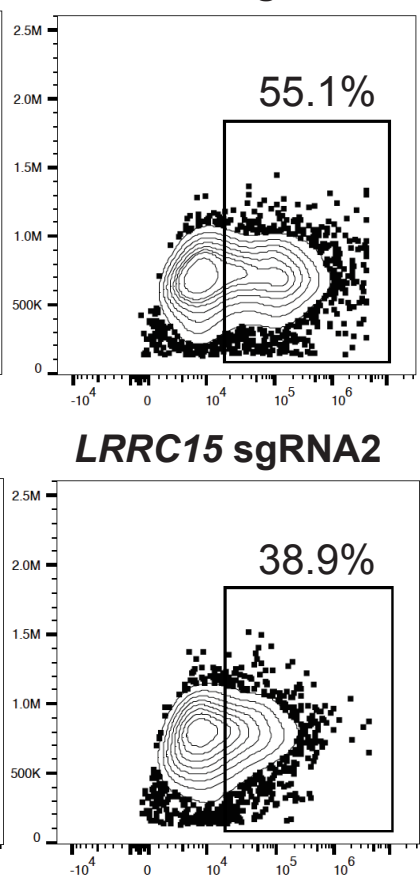

$488 \mathrm{~nm}$ intensity
LRRC15 sgRNA3

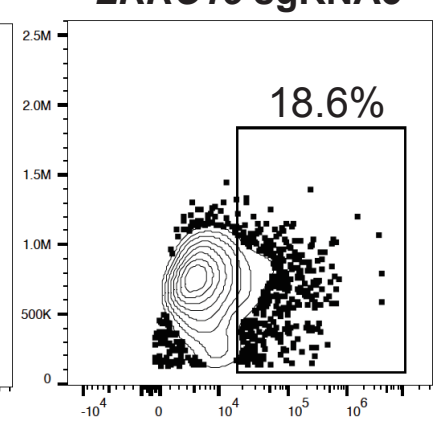

F

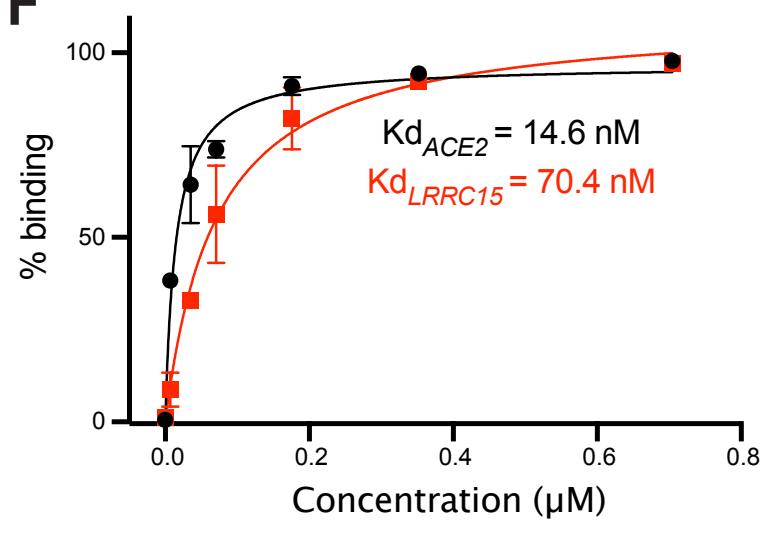




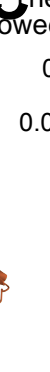

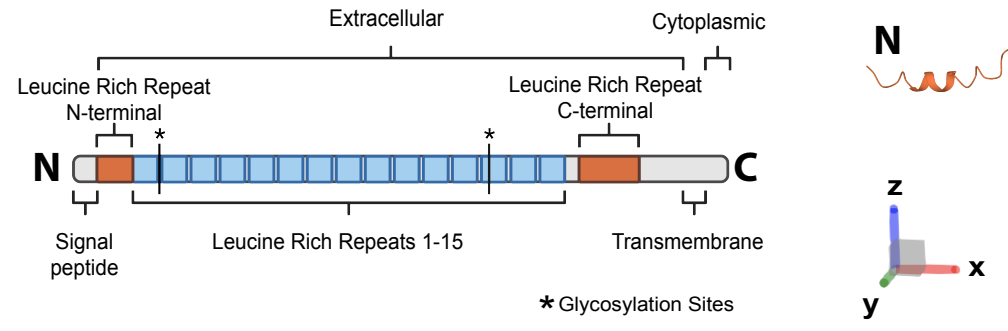
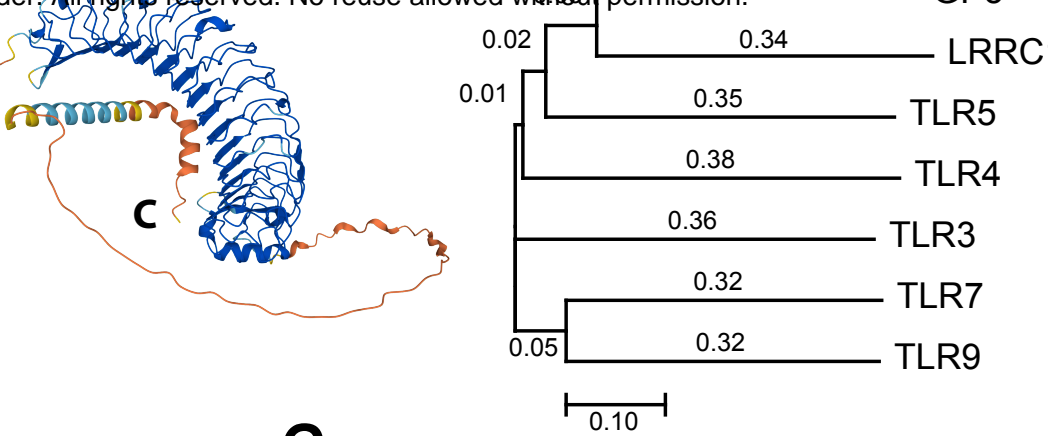

D WT

$\mathbf{E}$ $\mathbf{F}$ ACE2, TMPRSS2
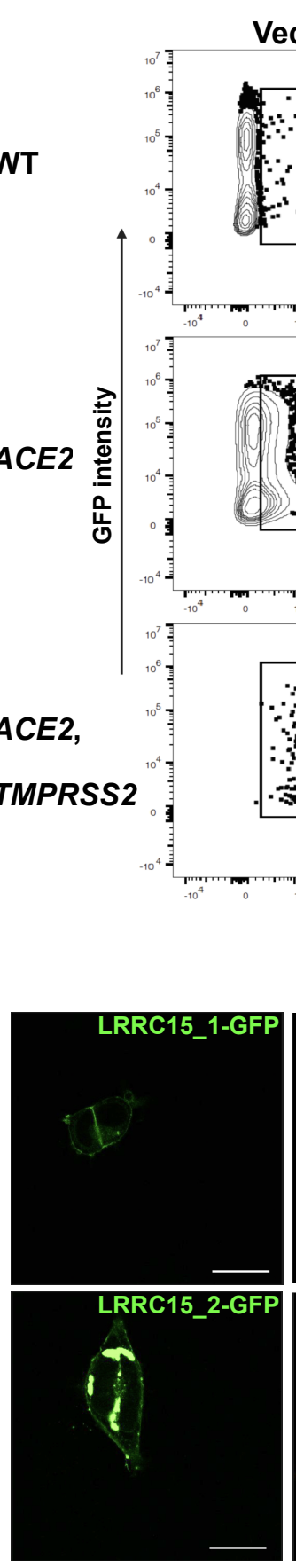

LRRC15_1
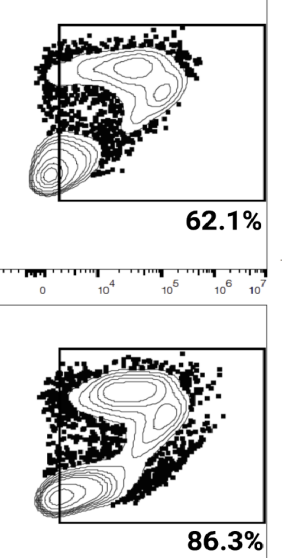

$48.8 \%$
LRRC15_2
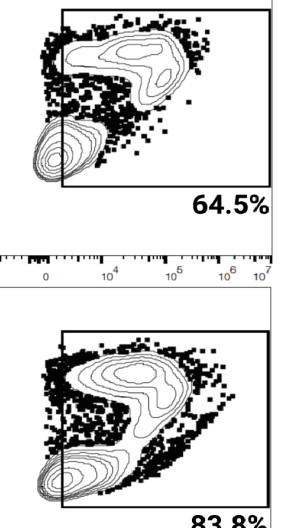

$\mathbf{8 3 . 8 \%}$

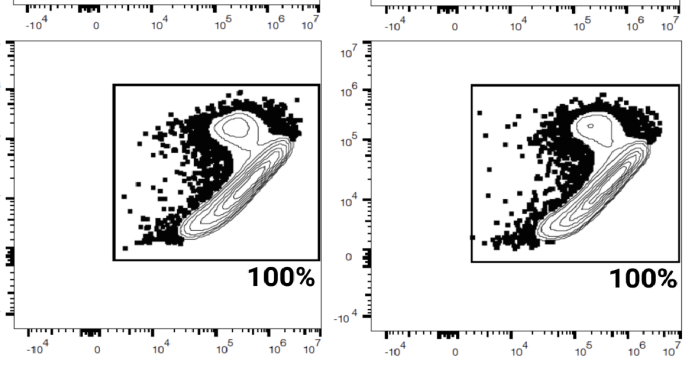

Spike647 intensity
G

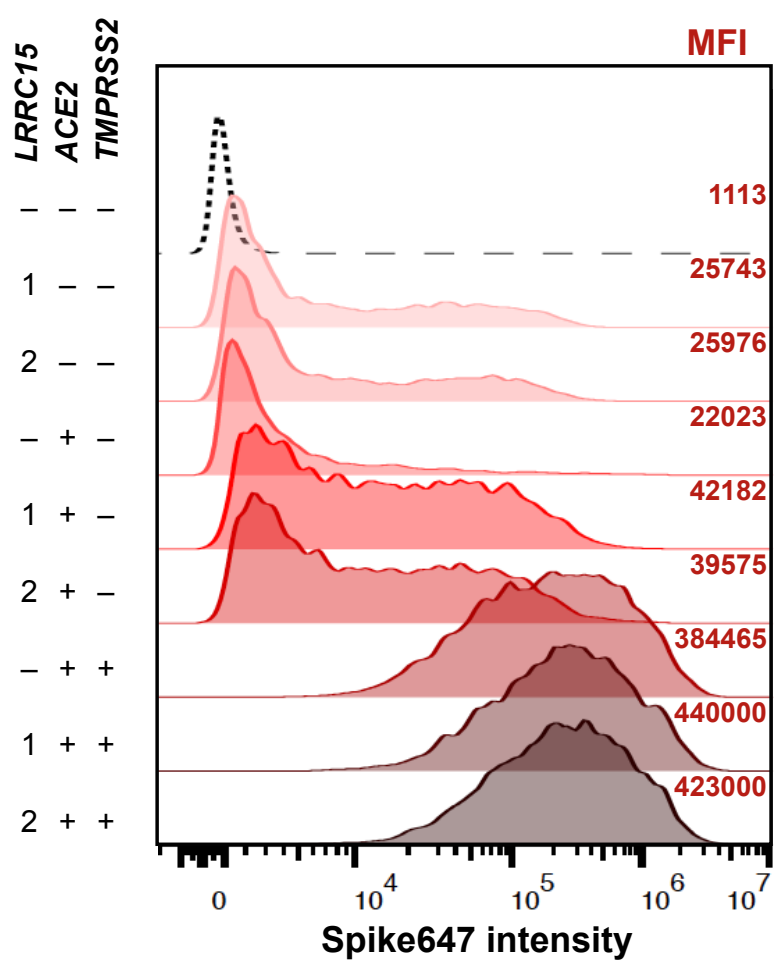

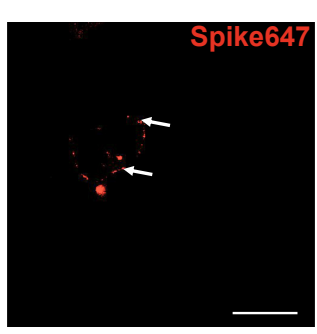
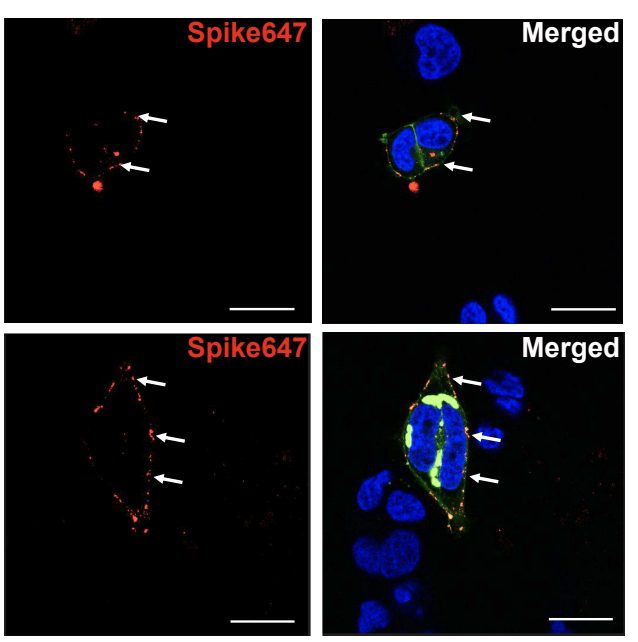

\section{LRRC15_1 LRRC15_2}

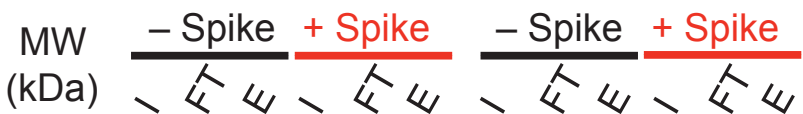
$250=$ 150 $100=$ 75 -
Spike

LRRC15-GFP 
bioRxiv preprint doi: https://doi.org/10.1101/202 B1.09.467981; this version posted November 10, 2021. The copyright holder for this preprint

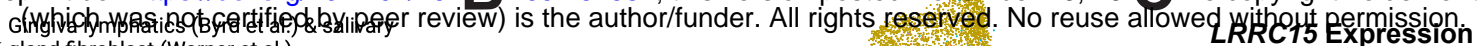
gland fibroblast (Warner et al.)

Esophagus lympathic vessels (Madissoon et

Thymus lymphatics (Fetal, Park et al.)

$\rightarrow$ Lung fibroblast (Vieira Braga et al., Maddisoon et al., Buechler et al., Delorey et al., Bharat et al., Melms et al.)

$\rightarrow$ Ileum fibroblast \& lymphatics (Martin et al.)

$\rightarrow$ Prostate fibroblast (Henry et al.) $\longrightarrow \begin{gathered}\text { Placenta Decidua stromal cell } \\ \text { (Vento-Tormo et al) }\end{gathered}$
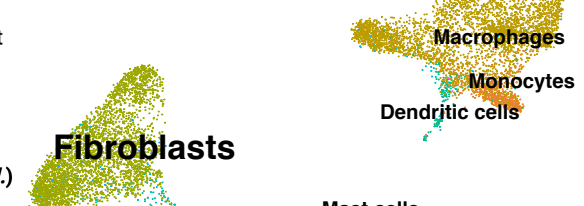

Dendritic cells

Smooth muscle Mast cells

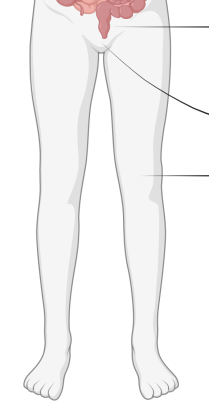

D

Airw

MonocytesEndothelial cells Cycling NK/T cells CD4+ T cells

Mast cells

Dendritic cells

$B$ cells

NK cells -

$\underset{\frac{7}{0}}{\frac{7}{0}}$

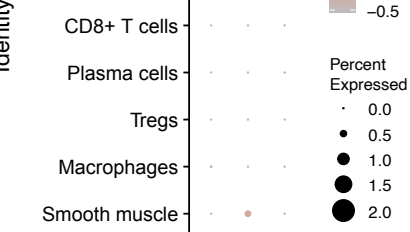

Other epithelial cells

Neuronal cells

Fibroblasts

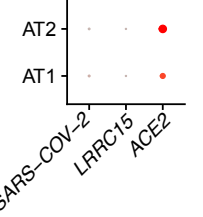

E

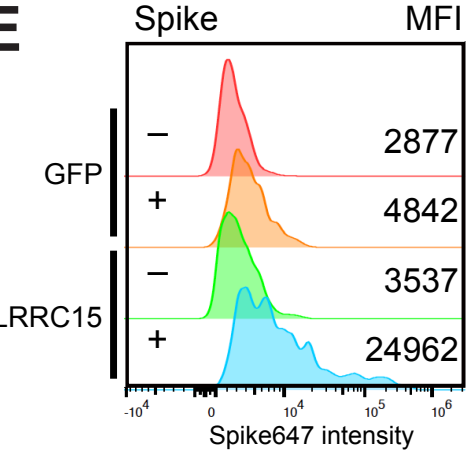

$G$

Average

2.5
-2.0

2.0
-1.5

1.0
0.5
0.0
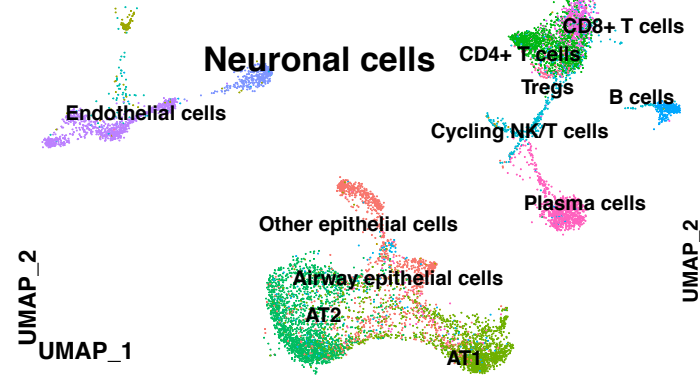

Neuronal cells CD4+ $\mathrm{T}$ CD8+T cells

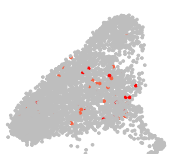

ells

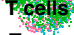

Cycling $\mathrm{NK} / \mathrm{T}$ cells

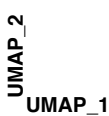

E
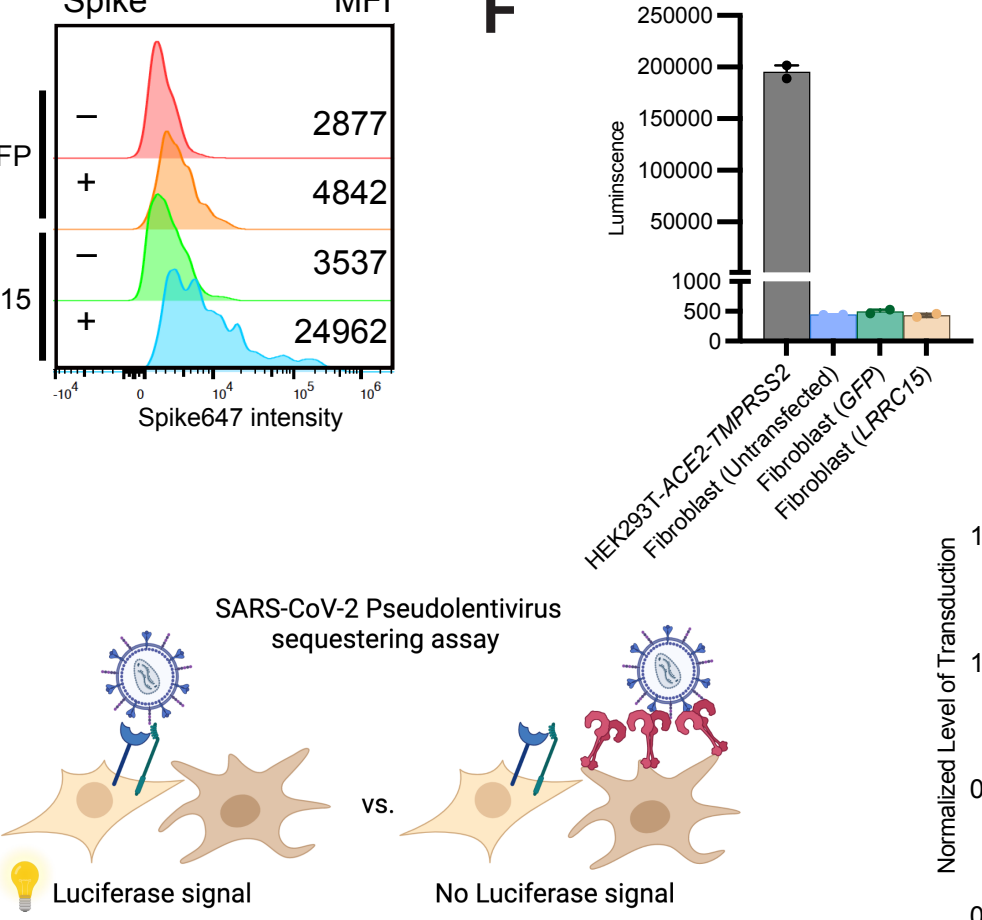

vs.

udolenti

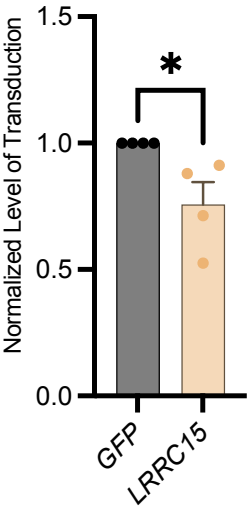

No Luciferase signal

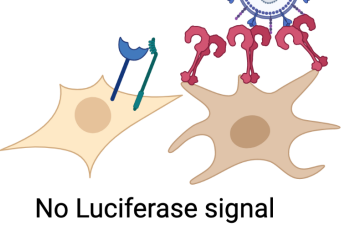


bioRxiv preprint doi: https://Dorg/10.1101/2021.11.09.467981; this version posted November 10, 2021. The copyright holder for this preprint Fibroblastisch was not ceflfied by peer review) is the author/funder. All rights reserved. No reuse allowed without permission.
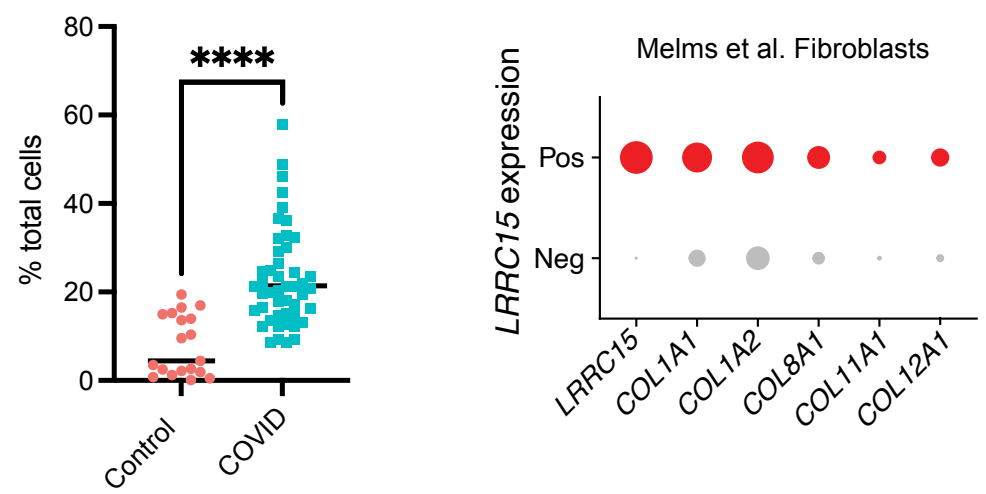

Delorey et al. Fibroblasts

Bharat et al. Fibroblasts

$-0.4$ 0.0

$-0.4$

Percent

Expressed

C

LRRC15

D COL1A1

E

LRRC15
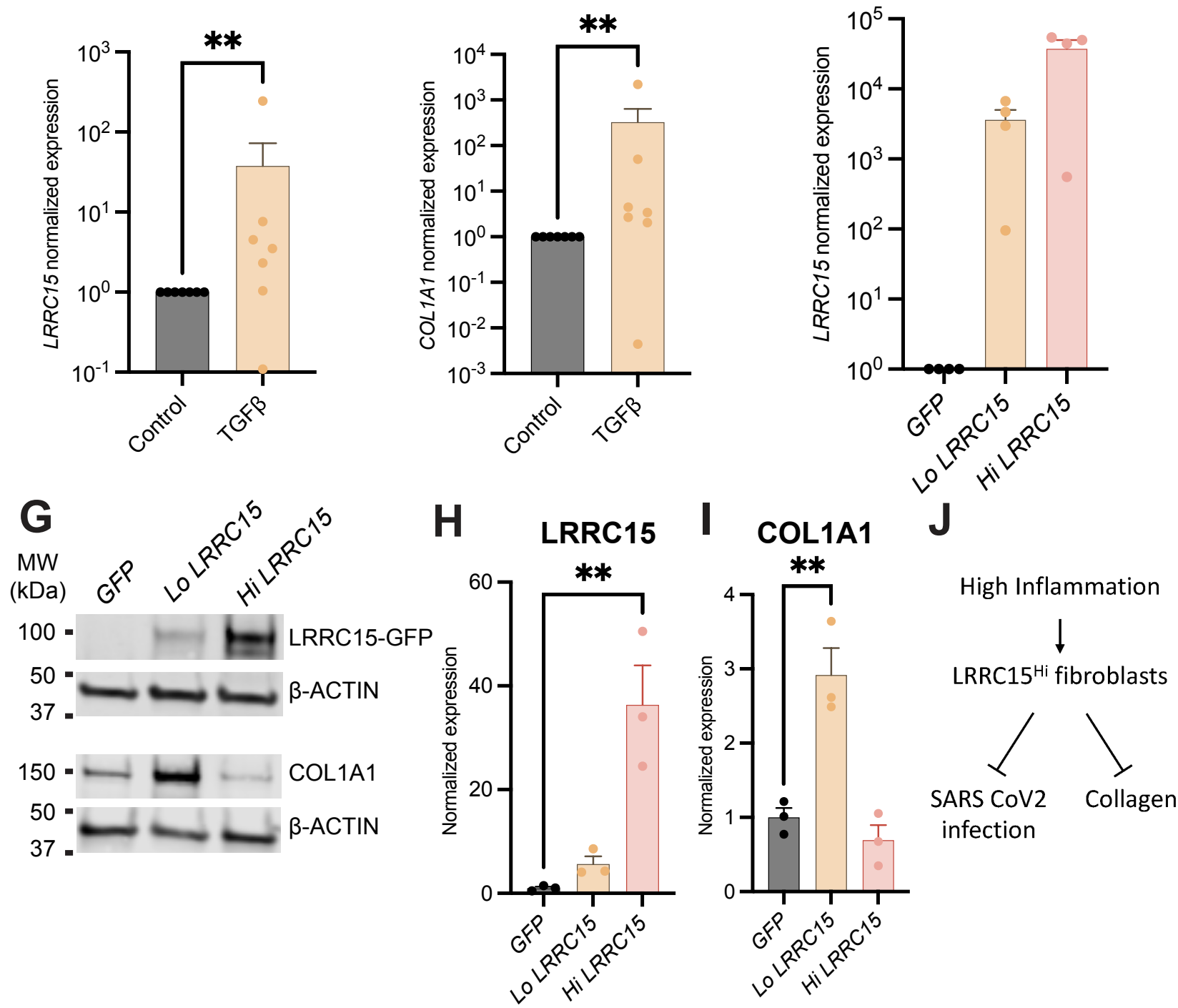

COL1A1

150

$\beta$-ACTIN

37 .
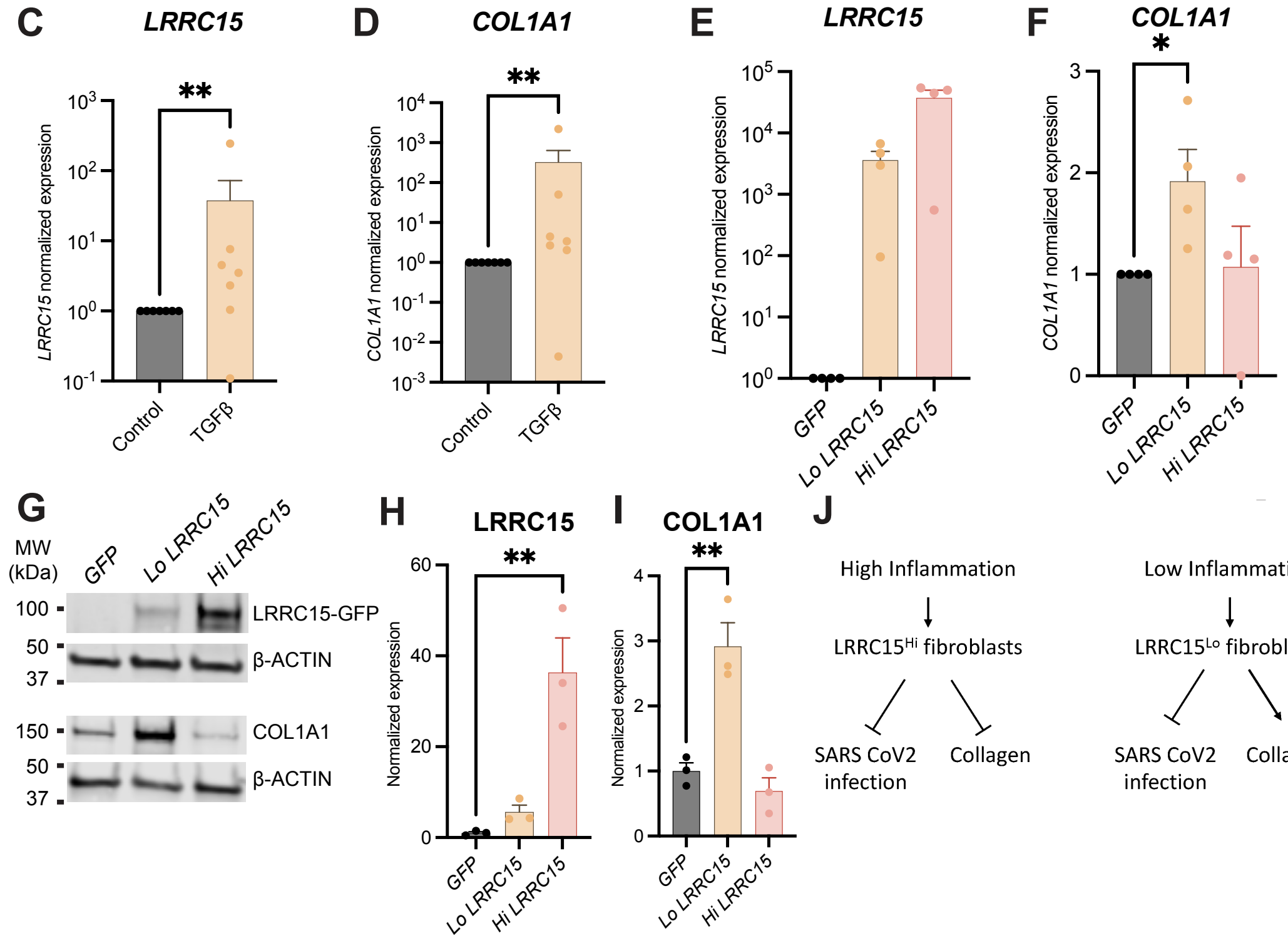

- 0

- 25
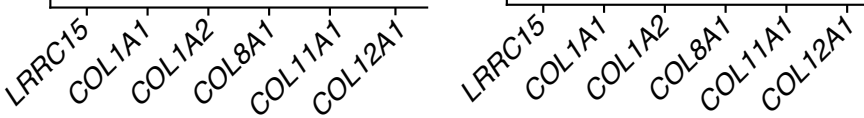

- 50

100

Low Inflammation

LRRC15 ${ }^{\text {Lo }}$ fibroblasts

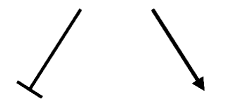

SARS CoV2 Collagen infection 

A bioRxiv preprint doi: \$\$ptps://doi.org/10.1101/2021 11.09 .467981 ; this version posted November 10,2021 . The copyright holder for this preprint

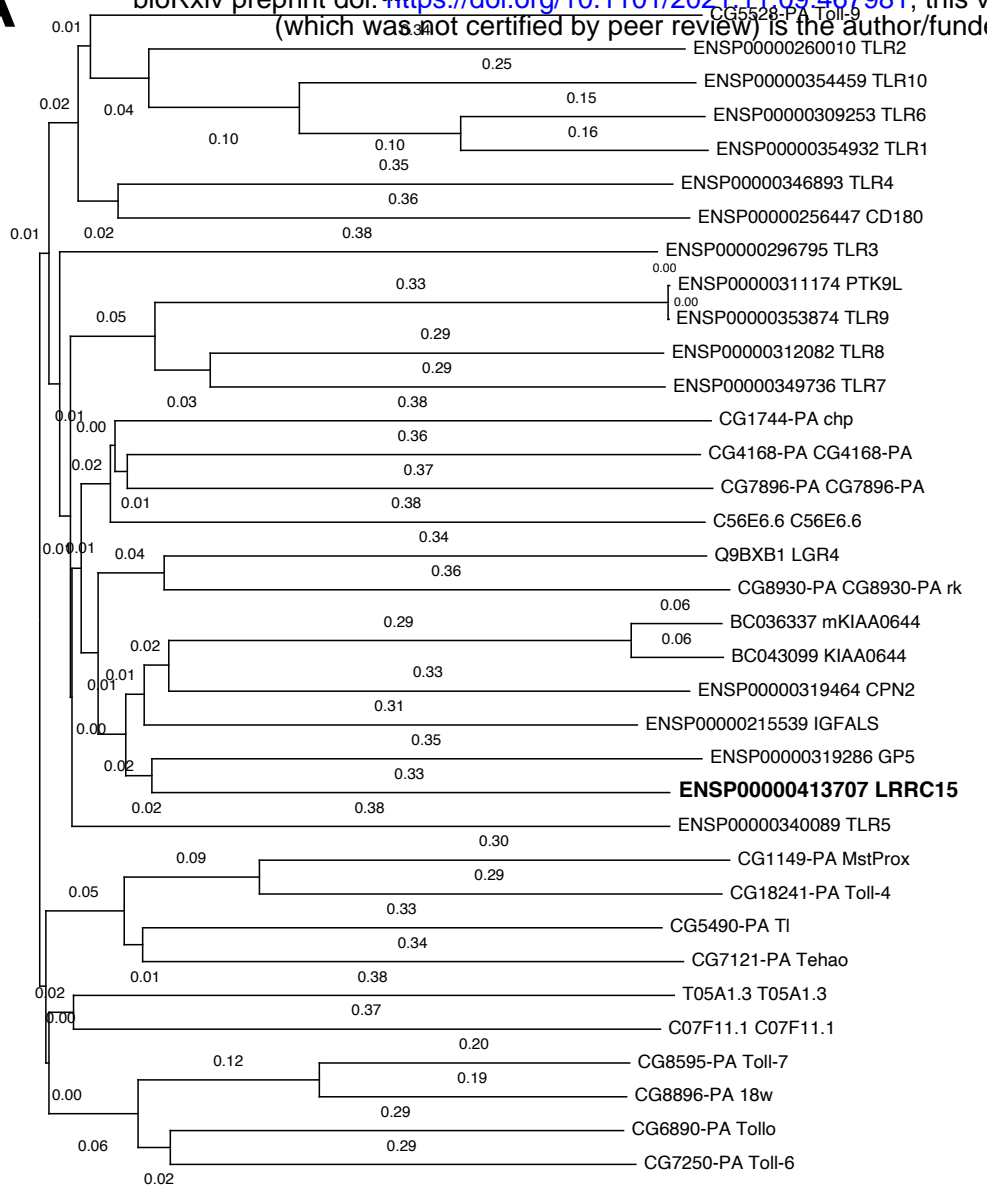

0.10

B

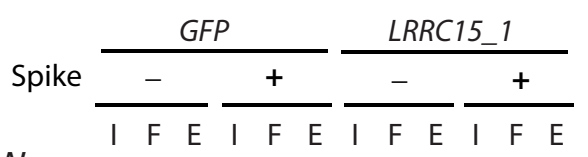

MW

$(\mathrm{kDa}$

$250-$

$150=$

$100=$

$75=$

250

150

100

75

250

150

$100-$

$75=$

C

Spike $\frac{\text { GFP }}{-+} \frac{\text { LRRC15_1 }}{-+} \frac{\text { LRRC15_2 }}{-+} \frac{\text { GFP }}{-+} \frac{\text { LRRC15_1 }}{-+} \frac{\text { LRRC15_2 }}{-+}$

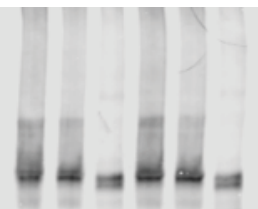

WT
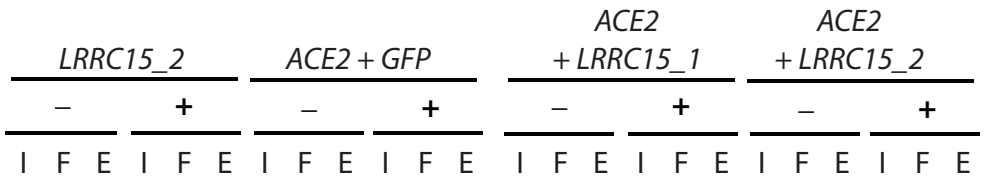

IP: anti-LRRC15

IB: anti-Spike, anti-LRRC15
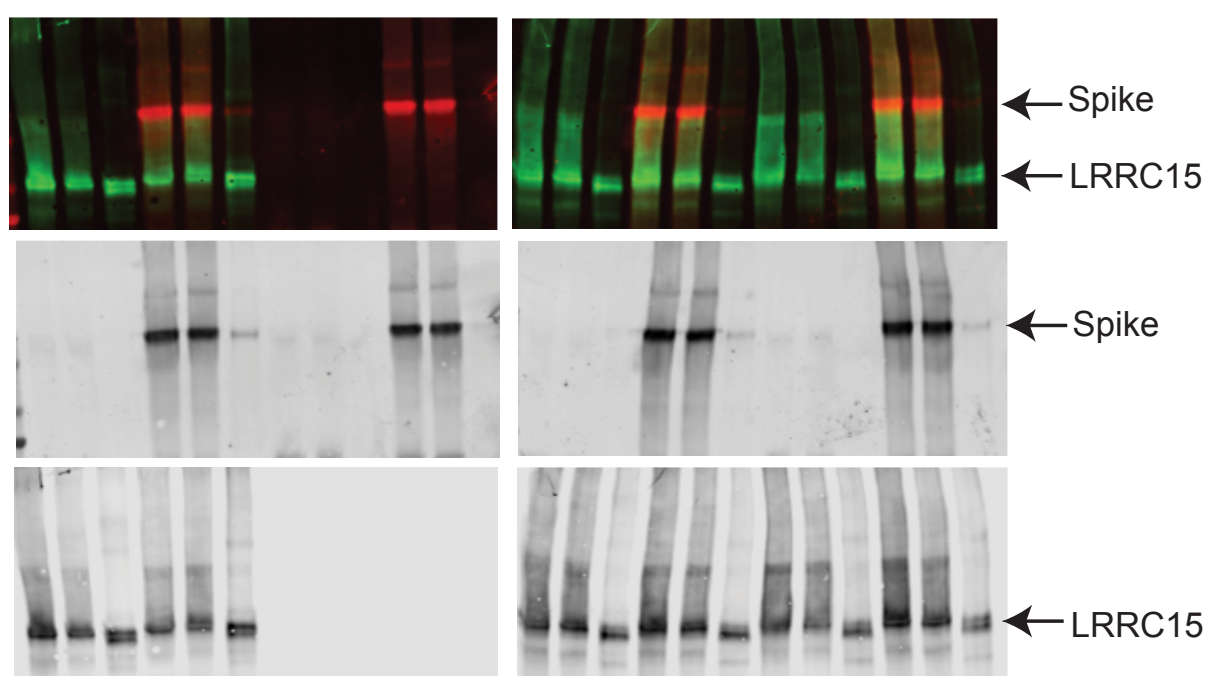

IP: rabbit-IgG

IB: anti-Spike, anti-LRRC15

$\overline{F E} \overline{F E} \overline{F E} \overline{F E} \overline{F E} \overline{F E} \overline{F E} \overline{F E} \overline{F E} \overline{F E} \overline{F E}$

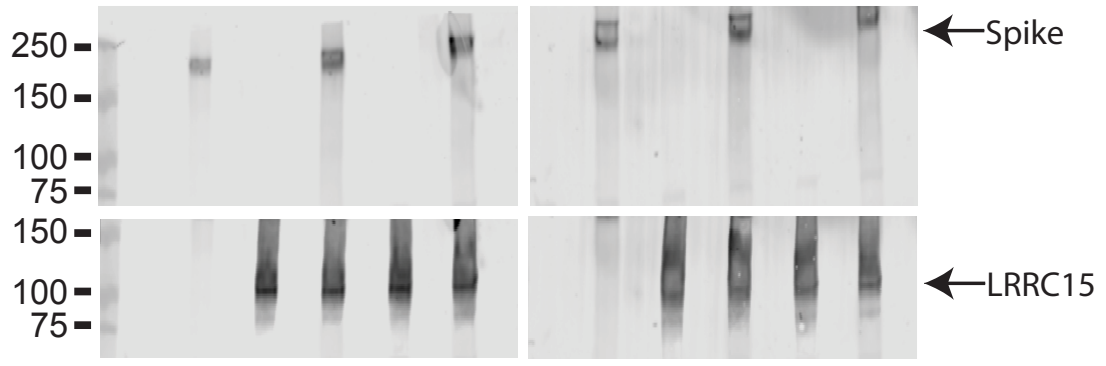




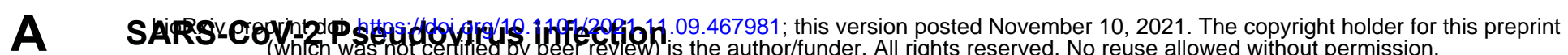

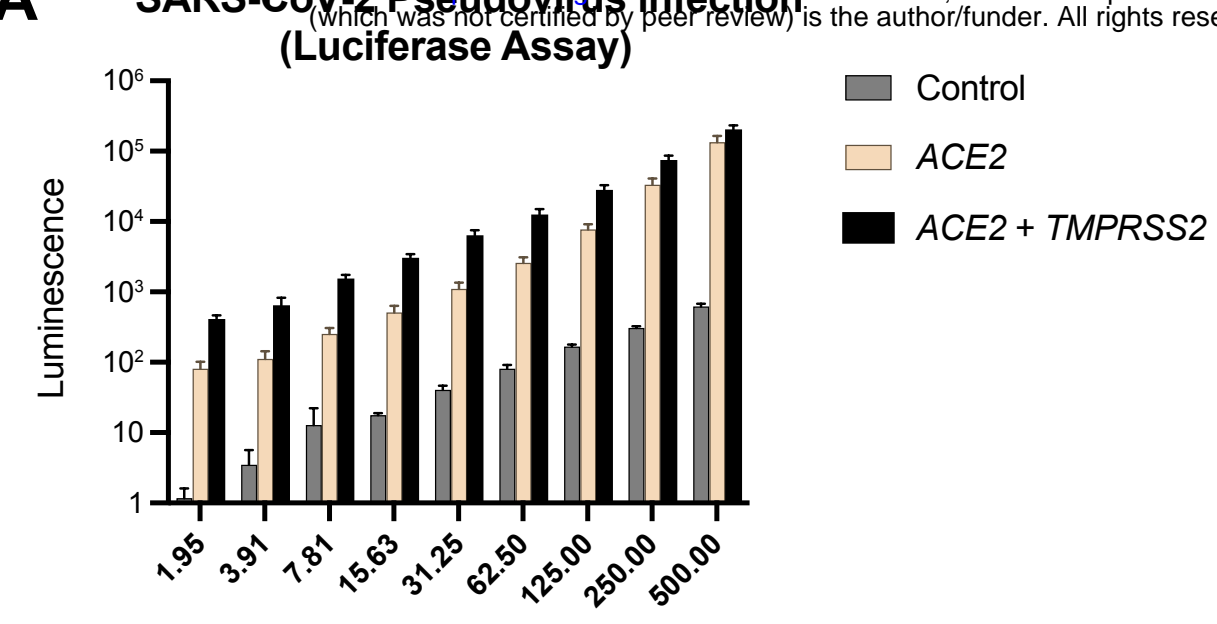

Pseudovirus particles $\left(10^{6}\right)$

B $15.6 \times 10^{\wedge} 6$ LVP

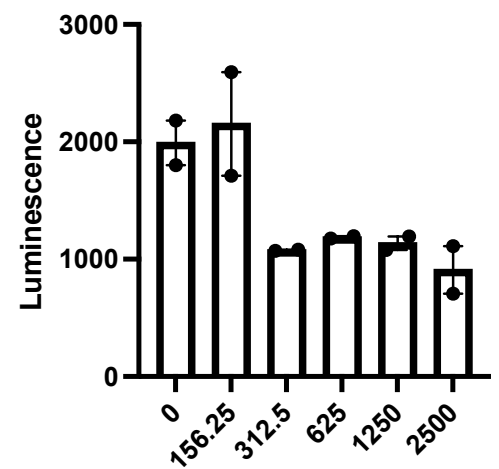

LRRC15 cDNA (ng)

C

HEK293T-ACE2
$62.5 \times 10^{\wedge} 6$ LVP

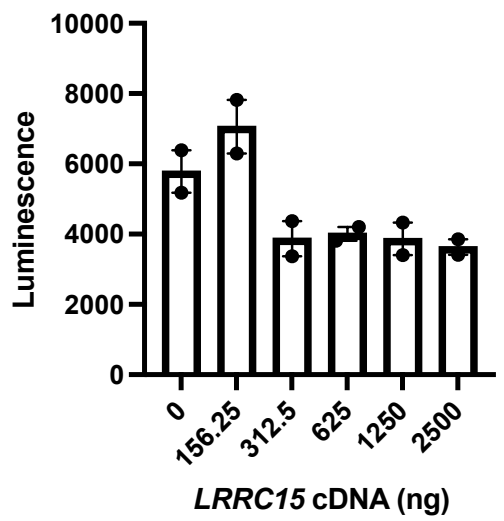

$250 \times 10^{\wedge} 6$ LVP

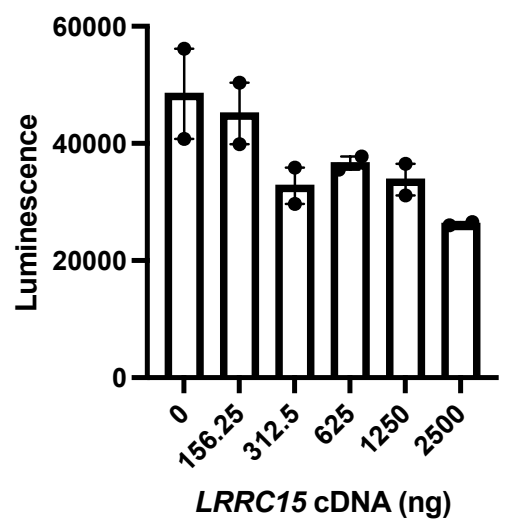

$1000 \times 10^{\wedge} 6$ LVP

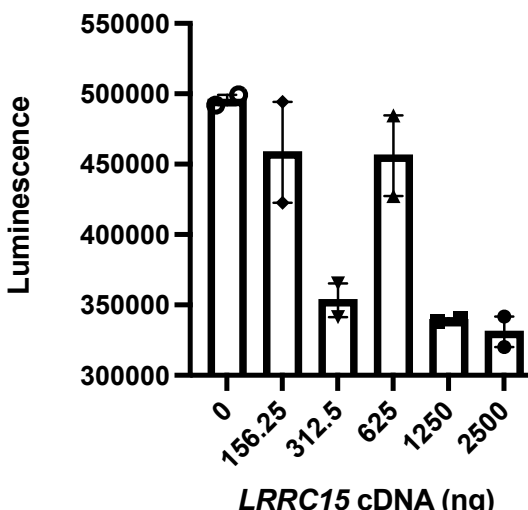

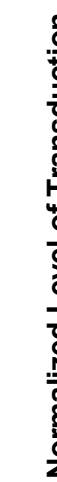

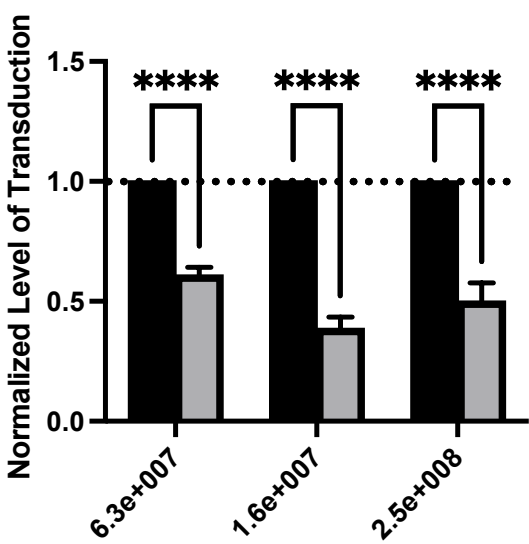

Pseudovirus particles

Control

LRRC15 
A
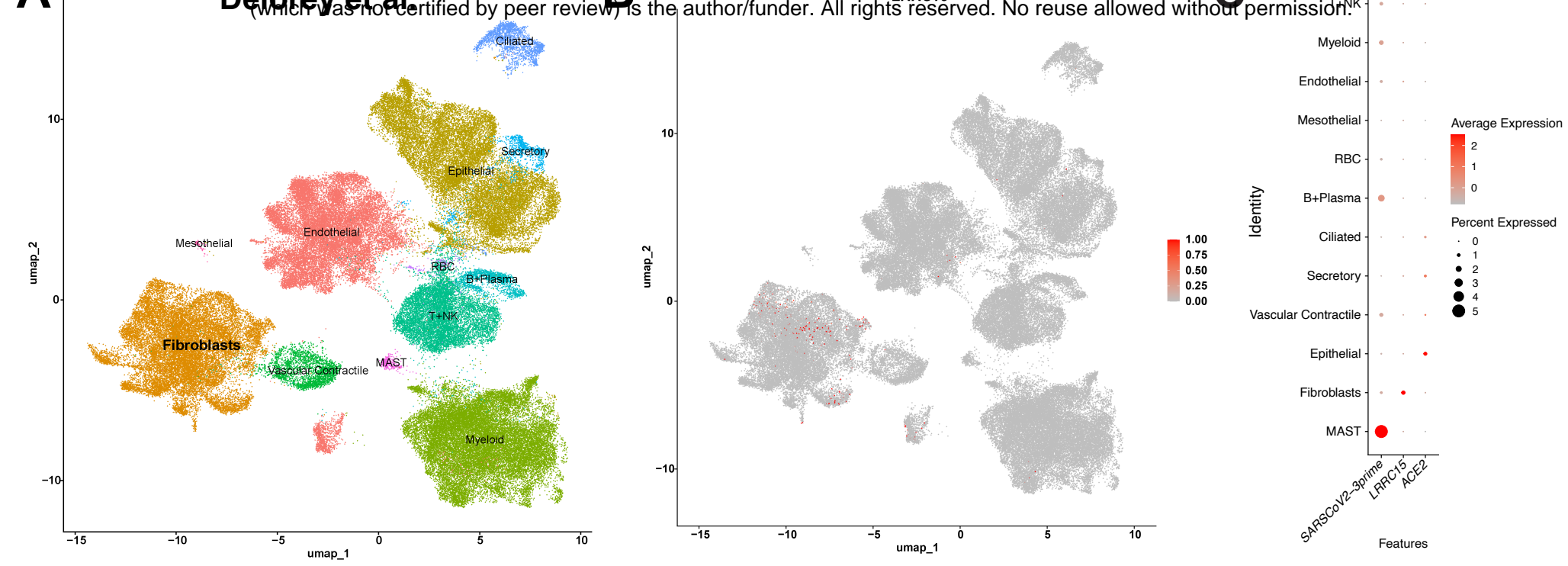

D

Bharat et al.

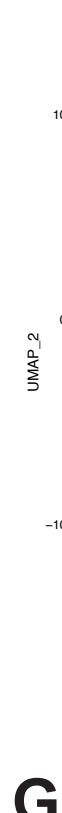

G
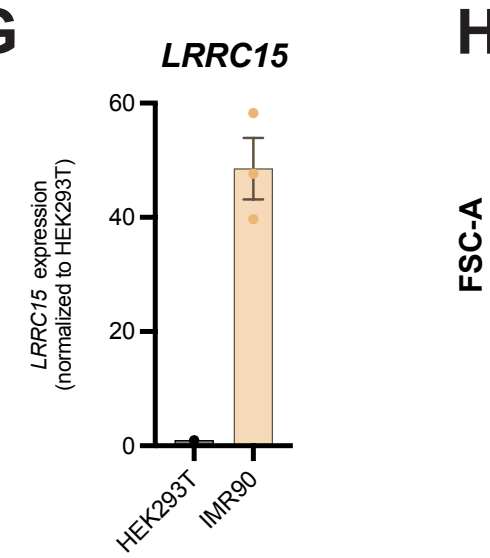

E

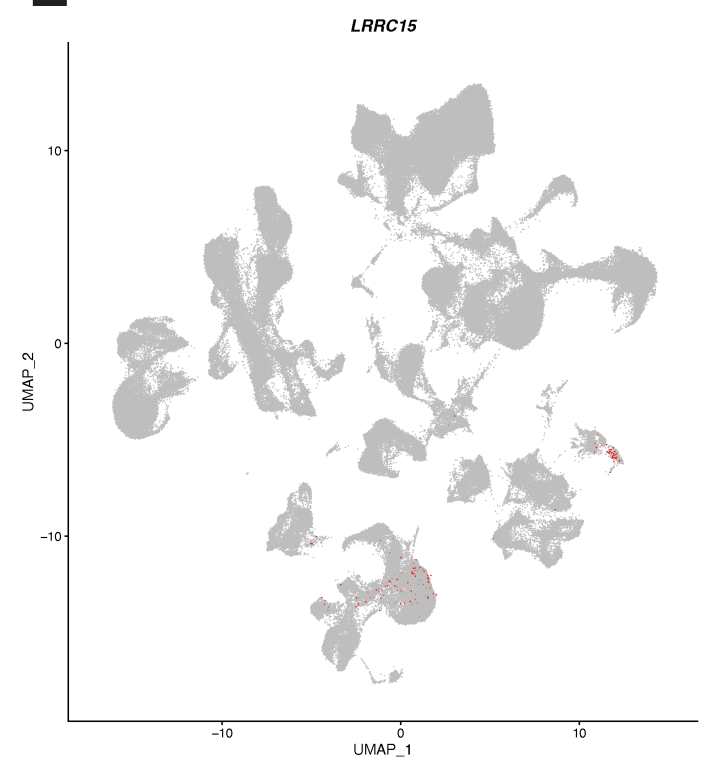

+ Spike647
H Untreated

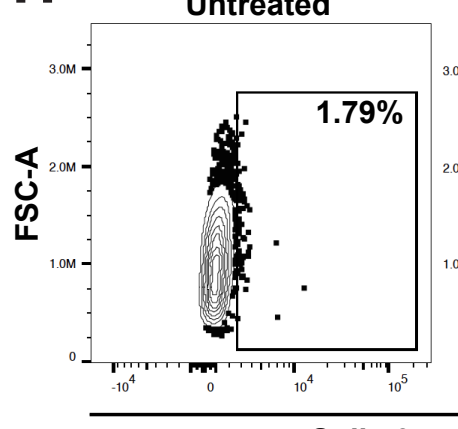

Spike647 (intensity)
F

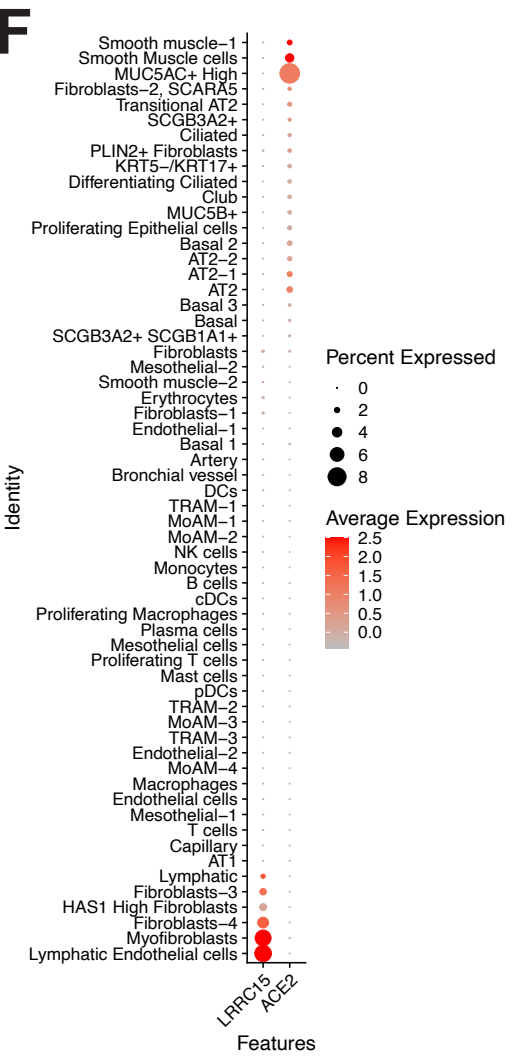


bioRxiv preprint doi: https://doi.org/10.1101/2021.11.09.467981; this version posted November 10, 2021. The copyright holder for this preprint

A (which wasूnot gertified by

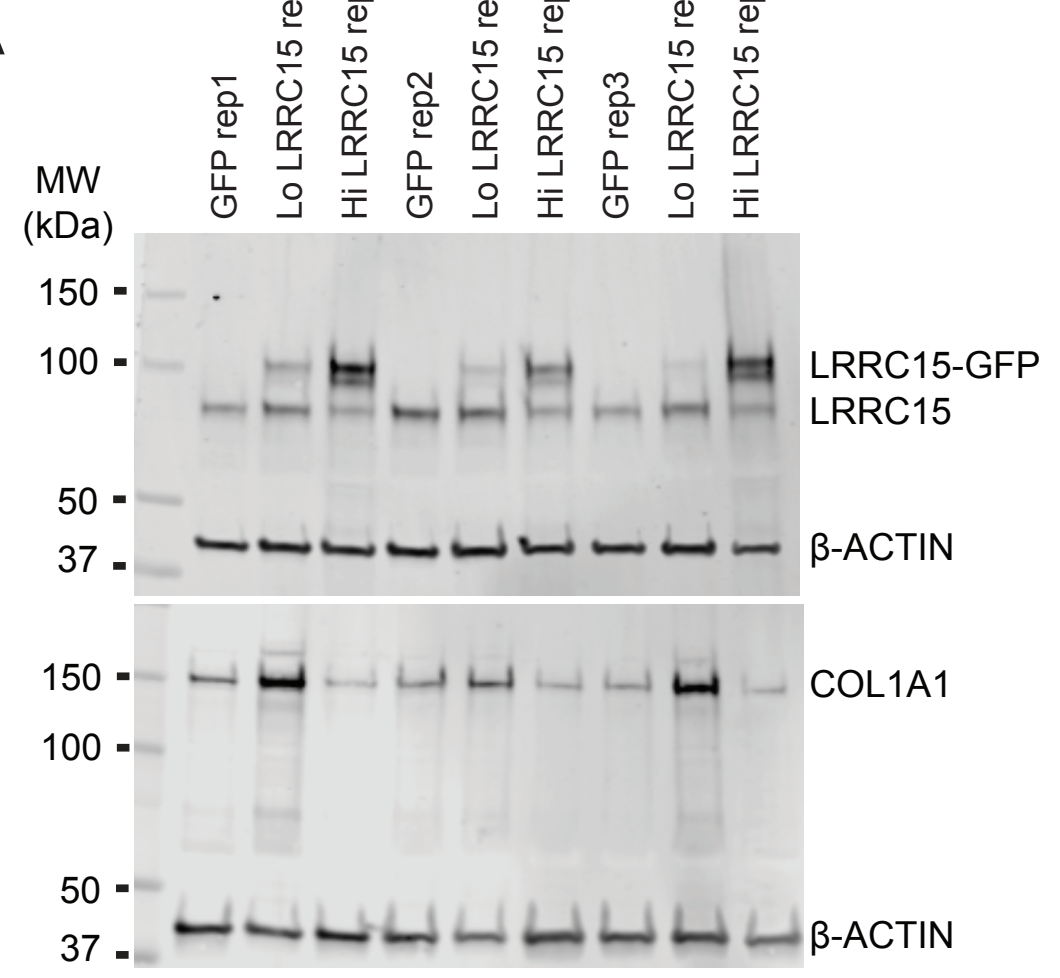

B

\section{Endogenous \\ LRRC15}

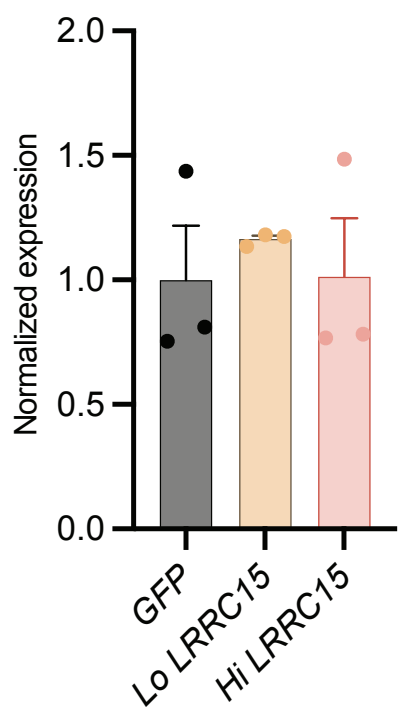

